\title{
Neurobiological Interactions Between Stress and the Endocannabinoid System
}

\author{
Maria Morena ${ }^{1,2}$, Sachin Patel ${ }^{3}$, Jaideep S Bains ${ }^{1,4}$ and Matthew N Hill${ }^{\star, 1,2,5}$ \\ ${ }^{1}$ Hotchkiss Brain Institute, University of Calgary, Calgary, AB, Canada; ${ }^{2}$ Mathison Centre for Mental Health Research and \\ Education, University of Calgary, Calgary, AB, Canada; ${ }^{3}$ Department of Molecular Physiology and Biophysics and Psychiatry, \\ Vanderbilt Brain Institute, Vanderbilt-Kennedy Center for Research on Human Development, Vanderbilt University Medical \\ Center, Nashville, TN, USA; ${ }^{4}$ Department of Physiology and Pharmacology, University of Calgary, Calgary, AB, Canada; \\ ${ }^{5}$ Departments of Cell Biology and Anatomy and Psychiatry, University of Calgary, Calgary, AB, Canada
}

Stress affects a constellation of physiological systems in the body and evokes a rapid shift in many neurobehavioral processes. A growing body of work indicates that the endocannabinoid (eCB) system is an integral regulator of the stress response. In the current review, we discuss the evidence to date that demonstrates stress-induced regulation of eCB signaling and the consequential role changes in $\mathrm{ECB}$ signaling have with respect to many of the effects of stress. Across a wide array of stress paradigms, studies have generally shown that stress evokes bidirectional changes in the two eCB molecules, anandamide (AEA) and 2-arachidonoyl glycerol (2-AG), with stress exposure reducing AEA levels and increasing 2-AG levels. Additionally, in almost every brain region examined, exposure to chronic stress reliably causes a downregulation or loss of cannabinoid type 1 (CB1) receptors. With respect to the functional role of changes in eCB signaling during stress, studies have demonstrated that the decline in AEA appears to contribute to the manifestation of the stress response, including activation of the hypothalamic-pituitary-adrenal (HPA) axis and increases in anxiety behavior, while the increased 2-AG signaling contributes to termination and adaptation of the HPA axis, as well as potentially contributing to changes in pain perception, memory and synaptic plasticity. More so, translational studies have shown that eCB signaling in humans regulates many of the same domains and appears to be a critical component of stress regulation, and impairments in this system may be involved in the vulnerability to stress-related psychiatric conditions, such as depression and posttraumatic stress disorder. Collectively, these data create a compelling argument that eCB signaling is an important regulatory system in the brain that largely functions to buffer against many of the effects of stress and that dynamic changes in this system contribute to different aspects of the stress response.

Neuropsychopharmacology Reviews (2016) 41, 80-102; doi:10.1038/npp.2015.166; published online 8 July 2015

\section{INTRODUCTION}

\section{Basic Primer on Stress}

The stress response is a biological cascade of events that occurs in response to a real or perceived threat to homeostasis. It requires the coordinated activation of a constellation of physiological systems that act to promote the survival of the organism. Typically, the response to physiological and/or psychological stressors requires the concerted activation of two parallel responses: an autonomic response and a neuroendocrine response. The autonomic response involves stimulation of sympathetic motor and hormonal outputs via

${ }^{*}$ Correspondence: Dr MN Hill, Departments of Cell Biology and Anatomy, University of Calgary, 3330 Hospital Drive NW, Calgary, AB T2N4N1, Canada, Tel: +1 403220 8466, Fax: +1 403283 2700,

E-mail: mnhill@ucalgary.ca

Received 12 March 2015; revised 20 May 2015; accepted 20 May 2015; accepted article preview online 12 June 2015 descending neural circuits originating in hypothalamic preautonomic control centers and results in the release of catecholamines within the brain and circulation. The neuroendocrine stress response is mediated by activation of the hypothalamic-pituitary-adrenal (HPA) axis, which results in an increase in circulating corticosteroids that target multiple organ systems (Pecoraro et al, 2006). Stress exposure also provokes a shift in many neurobehavioral processes, such as anxiety/vigilance, memory, reward salience, pain sensitivity, and coping behaviors (McEwen, 2012a). Collectively, these changes in biological function produce coordinated and highly adaptive responses that are conducive to survival in response to a threat.

Decades of basic and clinical research have delineated several well-defined brain circuits that are important for the manifestation of the physiological response to psychological stressors. Although these circuits have been discussed at great length in more focused reviews (see Hermans et al, 
2014b; Sparta et al, 2013; Ulrich-Lai and Herman, 2009), we will outline those relevant to the current review. In brief, sensory information regarding the external environment is processed by the thalamus and primary sensory cortical centers and funneled to the amygdala through a network of corticothalamic afferents. Of particular importance to stress is the transmission of information to nuclei of the amygdala and extended amygdala where preconscious threat detection occurs, emotional valence is ascribed, and reference to previous experiences occurs through crosstalk with the medial prefrontal cortex (mPFC) and hippocampus (Bishop, 2008; Hermans et al, 2014a; Likhtik and Paz, 2015; Roozendaal et al, 2009). This triadic circuit of the amygdala-mPFC-hippocampus has been found to be relevant for almost every neurobehavioral response to psychological stress (McEwen, 2012a). In general, activation of output pyramidal neurons of the basolateral amygdala (BLA) contributes to many aspects of stress, including HPA axis activation, anxiety, pain sensitivity, and alterations in cognitive processes through the trans-synaptic recruitment of downstream circuits, such as the central amygdala (CeA), medial amygdala, bed nucleus of the stria terminalis (BNST), nucleus accumbens, and distinct hypothalamic nuclei such as the lateral, anterior, and dorsomedial hypothalamus (Hermans et al, 2014b; Janak and Tye, 2015; Ulrich-Lai and Herman, 2009; Veinante et al, 2013). Conversely, excitatory inputs from the $\mathrm{mPFC}$ and hippocampus dampen amygdala output (Hubner et al, 2014; Likhtik et al, 2005). Consistent with this, damage to either of these structures typically results in amplified responses to stress and impairments in termination of the stress response (McEwen, 2012b; Radley, 2012), and in humans, reduced functional connectivity of these circuits, or hyperactivity of the amygdala, results in increased anxiety and sensitivity to stress (Kim et al, 2011; Pruessner et al, 2010; Swartz et al, 2015). Given the demonstrated importance of these circuits in the regulation of the neurobehavioral effects of stress, this review will focus on the mechanisms and functional contributions endocannabinoid (eCB) signaling has within these circuits with respect to the regulation of various aspects of the stress response.

\section{Basic Primer on the eCB System}

The eCB system nomenclature derives from the finding that eCBs and plant-derived cannabinoids converge on a common molecular receptor target (Mechoulam and Parker, 2013). The eCB system is a neuromodulatory lipid system, which consists of the cannabinoid receptor type 1 and type 2 (CB1 and CB2 receptors, respectively; Devane et al, 1992; Herkenham et al, 1990; Matsuda et al, 1990) and two major endogenous ligands, $\mathrm{N}$-arachidonyl ethanolamine (anandamide, AEA; Devane et al, 1992) and 2-arachidonoyl glycerol (2-AG; Sugiura et al, 1995). CB receptors are the primary molecular target of plant-derived tetrahydrocannabinol and couple to $G_{i / o}$ proteins that function to inhibit adenylyl cyclase activity, activate potassium channels, and inhibit voltage-gated calcium channels (Howlett et al, 2002). As CB1 receptors are primarily localized to axon terminals, activation of these receptors results in a robust suppression of neurotransmitter release into the synapse (Kano et al, 2009; Figure 1). CB1 receptors not only represent the most abundant class of G-protein-coupled receptors in the central nervous system (Herkenham et al, 1990) but are also present in a variety of peripheral tissues (Howlett et al, 2002). Within the brain, CB1 receptors are expressed on GABAergic, glutamatergic, serotonergic, noradrenergic, and dopaminergic terminals (Azad et al, 2008; Haring et al, 2007; Hermann et al, 2002; Kano et al, 2009; Morozov et al, 2009; Oropeza et al, 2007), but given the relative abundance of excitatory and inhibitory neurons in the brain, and the high levels of CB1 receptor expression on these terminals, the predominant effects of eCB signaling occur at GABAergic and glutamatergic synapses (Katona and Freund, 2012). CB2 receptors are mostly located in immune cells and, when activated, can modulate immune cell migration and cytokine release both outside and within the brain (Pertwee, 2005). There is also evidence that they are possibly expressed by some neurons (Atwood et al, 2012; Van Sickle et al, 2005), but the role of these putative neuronal $\mathrm{CB} 2$ receptors has yet to be established (Atwood and Mackie, 2010). In addition, some eCB ligands are active at other receptor targets, including peroxisome proliferator-activated receptor and transient receptor potential vanilloid type 1 , and can also directly affect activity of some ion channels (Di Marzo and Petrocellis, 2012).

AEA and 2-AG are synthesized 'on demand' from phospholipid precursors in the postsynaptic membrane by $\mathrm{Ca}^{2+}$-dependent and -independent mechanisms (Kano et al, 2009) and feedback in a retrograde manner onto presynaptic terminals, thus suppressing afferent neurotransmitter release via activation of CB1 receptors (Ohno-Shosaku and Kano, 2014). The process by which this release and transmission across the synapse occurs still remains enigmatic, but the collective electrophysiological and biochemical evidence to date strongly supports a model of postsynaptic synthesis and a presynaptic site of action (see Figure 1). The synthesis of $2-A G$ is tightly coupled to the generation of diacylglycerol from phospholipase $\mathrm{C}$ activity, which is rapidly converted to $2-\mathrm{AG}$ by the enzyme diacylglycerol lipase (Bisogno et al, 2003; Sugiura et al, 1995; Figure 1). The synthesis of AEA, on the other hand, is far less clear and appears to be performed by at least three redundant pathways, none of which have been verified as the primary source of AEA within the brain (Ahn et al, 2008; Figure 1). Following release into the synaptic cleft, AEA and 2-AG are subsequently taken back into the cell by a still poorly defined uptake process mediated by a transporter mechanism (Fu et al, 2011; Hillard et al, 1997) and primarily degraded by distinct hydrolytic enzymes, the fatty acid amide hydrolase (FAAH; Cravatt et al, 2001) and monoacylglycerol lipase (MAGL; Dinh et al, 2002), respectively (Figure 1). These two degrading enzymes display distinct subcellular localization, suggesting different signaling properties for AEA and 2-AG (Cristino et al, 2008; 


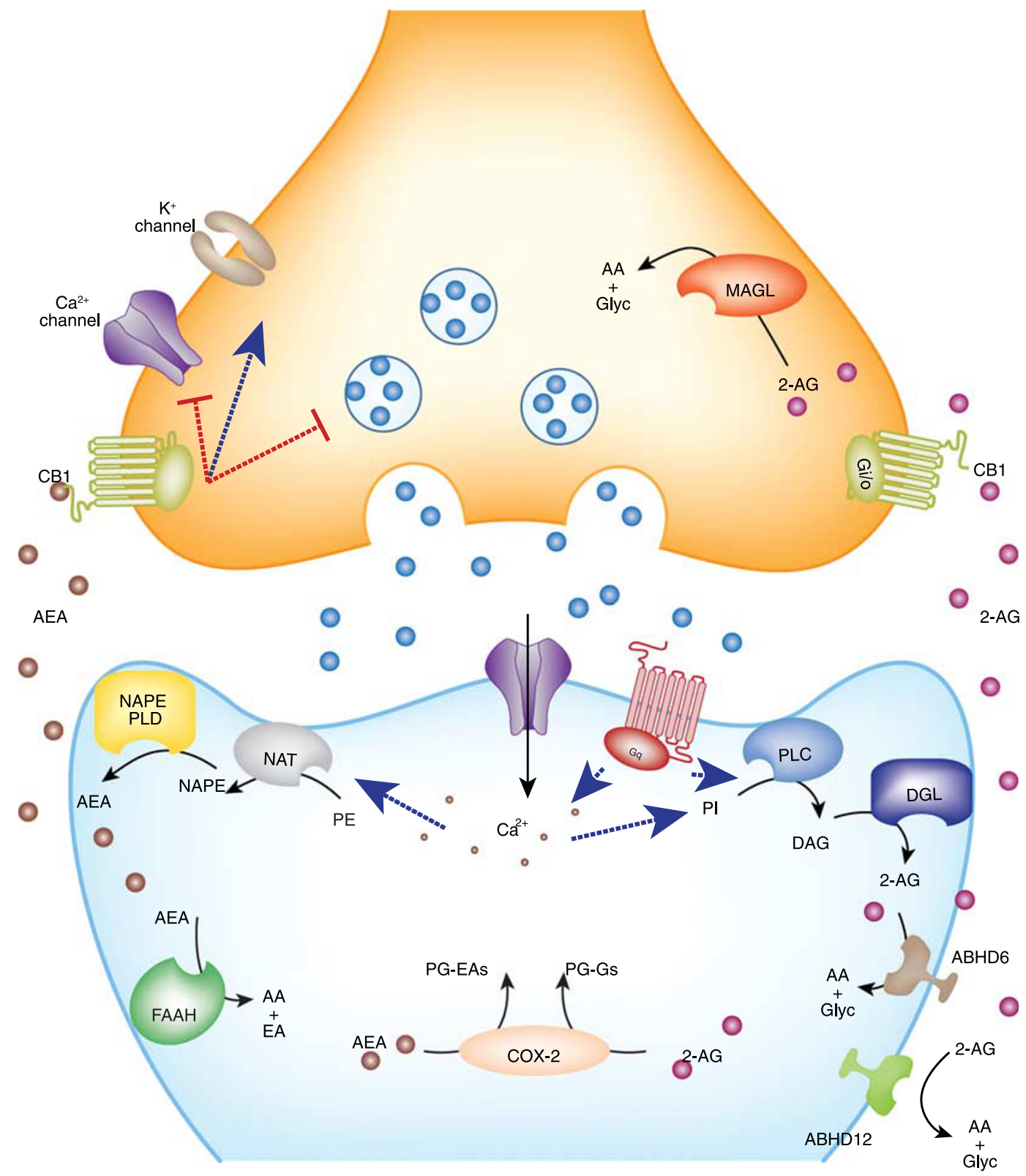

Figure 1. General model illustrating the retrograde endocannabinoid signaling. Upon release of neurotransmitter (eg, glutamate), postsynaptic depolarization causes increased intracellular $\mathrm{Ca}^{2+}$ levels through activation of AMPA, NMDA receptors and/or Gq-coupled receptors (eg, mGluR1/5) and voltage-gated $\mathrm{Ca}^{2+}$ channels. Intracellular $\mathrm{Ca}^{2+}$ elevation increases endocannabinoid biosynthesis, although there is evidence for $\mathrm{Ca}^{2+}$-independent forms of endocannabinoid synthesis as well. This model illustrates the two primary biosynthetic pathways for anandamide (AEA) and 2-arachidonoyl glycerol (2-AG), respectively. AEA is synthesized from phospholipid precursors (eg phosphatidylethanolamine, PE) by a Ca ${ }^{2+}$-dependent transacylase, $\mathrm{N}$-acyltransferase (NAT), yielding N-arachidonoyl PE (NAPE). NAPE is then hydrolyzed by a phospholipase D (NAPE-PLD) to yield AEA. Ca ${ }^{2+}$ influx and/or the activation of $\mathrm{G}_{\mathrm{q}}$-coupled receptors stimulate phospholipase $\mathrm{C}(\mathrm{PLC})$, which hydrolyses phosphatidylinositol (PI) into diacylglycerol (DAG). DAG is converted to 2-AG by diacylglycerol lipase (DGL). AEA and 2-AG then migrate from postsynaptic neurons to bind presynaptic-located cannabinoid type 1 (CB1) receptors. Once activated, $C B 1$ receptors couple through $\mathrm{G}_{\mathrm{i} / \mathrm{o}}$ proteins to inhibit adenylyl cyclase and regulate ion channels and ultimately suppress neurotransmitter release. Endocannabinoid signaling is then terminated by degrading enzymes. AEA is mainly hydrolyzed to arachidonic acid (AA) and ethanolamine (EA) by fatty acid amide hydrolase (FAAH), located postsynaptically. 2-AG is hydrolyzed presynaptically to AA and glycerol (Glyc) by monoacylglycerol lipase (MAGL), which accounts for 85\% of 2-AG hydrolysis, and postsynaptically by alpha-beta-hydrolase 6/12 (ABHD6/12), which accounts for the remainder of 2-AG hydrolysis. AEA and 2-AG are also oxygenated by cyclo-oxygenase 2 (COX-2) to form prostaglandin-ethanolamides (PG-EAs) and prostaglandin-glycerols (PG-Gs).

Kano et al, 2009). All studies to date have indicated that FAAH is predominantly located on intracellular membranes in postsynaptic cells, while MAGL is positioned in close proximity of $\mathrm{CB} 1$ receptors, in presynaptic terminals, at least within the brain regions that have been examined to date such as the hippocampus, amygdala, and cerebellum (Gulyas et al, 2004). In addition to these two primary metabolic enzymes, both AEA and 2-AG are also oxygenated by cyclo- 
oxygenase 2 (COX-2) to form bioactive prostaglandin derivatives (Hermanson et al, 2013; Figure 1). Additionally, a small proportion of $2-\mathrm{AG}$ is also metabolized by the alpha-beta hydrolase (ABHD) class of enzymes, specifically ABHD6 and ABHD12 (Blankman et al, 2007; Marrs et al, 2010; Figure 1). The functional role of these alternate metabolic pathways is not well characterized. For instance, due to its postsynaptic localization (Blankman et al, 2007; Marrs et al, 2010), it is likely that ABHD6 might be involved in the regulation of 2-AG levels released into the synaptic cleft. However, to date, studies have clearly identified the physiological significance of FAAH and MAGL as regulators of eCB levels as pharmacological or genetic inactivation of these two enzymes results in profound accumulation of AEA and 2-AG, respectively (Cravatt et al, 2001; Long et al, 2009).

In general, the activation of the $\mathrm{eCB}$ system at the synapse leads to a short or a sustained suppression of neurotransmitter release from the presynaptic compartment. Despite the fact that both AEA and 2-AG similarly act to regulate presynaptic transmitter release, it is believed that these two molecules of the eCB system may operate in phasic and tonic modes, thereby differentially mediating homeostatic, short-term, and long-term synaptic plasticity processes throughout the brain (Ahn et al, 2008; Hill and Tasker, 2012; Katona and Freund, 2012). It is thought that AEA represents the 'tonic' signaling molecule of the eCB system that acts to regulate basal synaptic transmission, whereas 2AG represents the 'phasic' signal activated during sustained neuronal depolarization and mediates many forms of synaptic plasticity (Ahn et al, 2008; Gorzalka et al, 2008; Katona and Freund, 2012).

There are several lines of evidence suggesting that the eCB system may be an important regulator of various aspects of the stress response. First, there is significant evidence within human populations that cannabis consumption typically results in a reduction of perceived stress, an increase in relaxation, and a dampening of feelings of anxiety (Green et al, 2003). Given that the physiological actions of cannabis are mediated by activation of the $\mathrm{CB} 1$ receptor, this suggested that a normative function of the $\mathrm{eCB}$ system could be to dampen or buffer against the effects of stress. Consistent with this hypothesis, pharmacological or genetic disruption of eCB signaling reliably produces a neurobehavioral phenotype, which directly parallels the classical manifestation of a stress response, including activation of the HPA axis, increased anxiety, suppressed feeding behavior, reduced responsiveness to rewarding stimuli, hypervigilance and arousal, enhanced grooming behavior, and impaired cognitive flexibility (Bellocchio et al, 2013; Friemel et al, 2014; Haller et al, 2004; Marsicano et al, 2002; Patel et al, 2004; Sanchis-Segura et al, 2004; Santucci et al, 1996; Shonesy et al, 2014; Tallett et al, 2007; Varvel and Lichtman, 2002). As such, these data indicate that there is a prominent stressinhibitory role of the eCB system. Anatomically, within the cortico-limbic circuit that regulates the stress response, $\mathrm{eCB}$ synthetic and degradative enzymes and CB1 receptors are prominently expressed in the amygdala (primarily in the BLA but also in the central nucleus as well; Ramikie et al, 2014; Ramikie and Patel, 2012), hippocampus, mPFC, and nucleus accumbens (Herkenham et al, 1991; Marsicano and Kuner, 2008; McPartland et al, 2007), where they modulate both excitatory and inhibitory signaling within specific neuronal circuits. For the purposes of the current review, we will focus on the role of the $\mathrm{CB} 1$ receptor and the $\mathrm{eCB}$ molecules AEA and 2-AG within discrete regions of this cortico-limbic circuit and how they interact with stress within the brain to modulate various aspects of the stress response.

\section{Stress Exposure Modulates the eCB System}

One of the initial lines of evidence suggesting that the eCB system may be involved in the stress response was the fact that this system was very reliably modulated by exposure to stress. The effects of stress on the eCB system appear to be quite complex, regionally specific, and time-dependent relative to exposure to stress and the chronicity of stress exposure. For the sake of clarity, we will discuss the nature in which stress modulates each component of the eCB system.

\section{Effects of Acute Stress on AEA Brain Levels}

Within the examined subcortical-limbic structures of the brain, exposure to acute stress generally causes a rapid reduction in tissue content of AEA in response to an array of psychological stressors. Within the amygdala, this effect appears to be quite prominent as exposure of both rats and mice to restraint stress causes a reduction in the tissue levels of AEA (Gray et al, 2015; Hill et al, 2009c; Patel et al, 2005b; Rademacher et al, 2008). Similarly, both acute restraint stress and social defeat stress have been found to reduce AEA content within the hippocampus (Dubreucq et al, 2012; Wang et al, 2012b). This reduction in AEA content is, at least in part, mediated by an increase in AEA hydrolysis by FAAH as acute stress increases FAAH activity within the amygdala (Gray et al, 2015; Hill et al, 2009c). Similarly, in the hippocampus, acute restraint stress increases FAAH protein levels $24 \mathrm{~h}$ after the stress exposure (Navarria et al, 2014). Interestingly, this effect appears to be conserved throughout the lifespan as early life stress in the form of maternal separation has also been shown to reduce AEA content within the hippocampus (Marco et al, 2013). Unlike the consistency seen in the amygdala and hippocampus, the mPFC seems to be somewhat of a more complex structure as exposure to swim stress has been found to produce a robust reduction of AEA content (McLaughlin et al, 2012), but neither acute restraint (Gray et al, 2015; Hill et al, 2011b; Rademacher et al, 2008) nor acute social defeat (Dubreucq et $a l, 2012$ ) were found to have any effect on AEA content in the mPFC. Similarly, restraint stress was found to have no effect on FAAH mRNA, protein, or activity within the mPFC (Gray et al, 2015; Navarria et al, 2014). 
It should be noted that footshock appears to be the one anomalous stressor with respect to the effects on AEA content. Two separate studies have both found that footshock actually elevates, not reduces, AEA levels in the mPFC, amygdala, hippocampus, and periaqueductal gray (Hohmann et al, 2005; Morena et al, 2014b). It is possible that the different nature of the stressful stimulus, the different behavioral paradigm used, or the additional painful component of footshock activate specific neuronal pathways that mobilize AEA to modulate diverse aspects of the stress response, such as memory (Morena et al, 2014b) and pain (Hohmann et al, 2005). Interestingly, Bluett et al (2014) have recently demonstrated a robust, brain-wide reduction in AEA content $24 \mathrm{~h}$ following exposure to footshock. This suggests that, although noxious stimuli, such as footshock, may rapidly elevate AEA content, there still appears to be a delayed reduction in AEA levels resulting in the typical stress-induced 'AEA-deficient' state (Bluett et al, 2014).

Mechanistically, the effects of stress on AEA appear to be rapid and may precede the onset of the HPA axis (GunduzCinar et al, 2013a; Hill et al, 2009c), suggesting that the signal mediating these effects was upstream of glucocorticoid release. Consistent with this, we have recently demonstrated that the neuropeptide corticotropin-releasing hormone $(\mathrm{CRH})$, which is rapidly released in response to stress (Merlo Pich et al, 1995; Roozendaal et al, 2002), increases FAAH activity following activation of $\mathrm{CRH}$ type 1 receptors (CRHR1) on glutamatergic neurons in the BLA (Gray et al, 2015). This reduces AEA signaling through a yet to be determined intracellular signaling mechanism. Interestingly, this interaction between CRH and FAAH did not occur within the mPFC (Gray et al, 2015), which may explain the unreliable effects of stress on AEA within the mPFC. It should be noted, however, that CRHR1 activation exerts similar effects on intracellular signaling pathways within the amygdala and hippocampus, by increasing pERK1/2 levels in both brain structures, without altering $\mathrm{pERK} 1 / 2$ expression in the CeA, paraventricular nucleus of the hypothalamus (PVN), or neocortex (Refojo et al, 2005). Thus this evidence creates a potential platform from which to explore the mechanisms linking stress, $\mathrm{CRH}$, and AEA signaling, and the regional specificity of this interaction. In terms of the recovery of this effect, it has been shown that administration of corticosterone can actually increase AEA levels within the amygdala (Hill et al, 2010a), suggesting that this may be part of the feedback loop through which AEA levels normalize following cessation of stress.

\section{Effects of Chronic Stress on AEA Brain Levels}

With respect to repeated or chronic stress, the nature of the stress exposure itself seems to have significant impact on changes in AEA content. Similar to what has been reported with exposure to acute stress, repeated exposure to the same stressor (chronic homotypic stress), such as restraint stress and social defeat stress, seems to reliably reduce AEA content in the amygdala (Hill et al, 2010b, 2013b; Patel et al, 2005b; Rademacher et al, 2008), hippocampus (Dubreucq et al, 2012; Hill et al, 2010b), hypothalamus (Dubreucq et al, 2012; Hill et al, 2010b), and mPFC (Hill et al, 2010b; Rademacher et al, 2008). Similar to acute stress, this reduction in AEA has been coupled to an increase in FAAH activity, at least within the amygdala, and FAAH KO mice do not exhibit any changes in AEA content within the amygdala in response to repeated stress (Hill et al, 2013b). These effects of chronic homotypic stress on FAAH and AEA signaling are likely mediated by sustained exposure to corticosterone as models of chronic corticosterone exposure have similarly found increases in FAAH activity and reductions in AEA content within the amygdala, hippocampus, and mPFC (Bowles et al, 2012, Gray et al, unpublished data). However, these effects of corticosterone appear to still be mediated by a CRH mechanism as the ability of chronic corticosterone to increase FAAH and reduce AEA levels are reversed by CRHR1 antagonist and mimicked by forebrain overexpression of CRH (Gray et al, unpublished data). As chronic exposure to corticosterone is known to upregulate extra-hypothalamic $\mathrm{CRH}$, at least within the amygdala and extended amygdala (Makino et al, 1994a,b; Swanson and Simmons, 1989) and mPFC (Gray et al, unpublished data), this would suggest that a common $\mathrm{CRH}$ mechanism mediates both the acute and chronic stress effects on FAAH and AEA.

In contrast to homotypic stress, the effects of chronic heterotypic stress on AEA content are less consistent across studies. Although one study found reductions in AEA levels in all brain regions examined (PFC, hippocampus, amygdala, ventral striatum, hypothalamus, and midbrain) following 3 weeks of chronic unpredictable stress (CUS; (Hill et al, $2008 \mathrm{~b}$ ) and another found increased FAAH protein expression within the hippocampus following CUS (Reich et al, 2009), several other studies have found no effect of CUS on AEA levels in several brain regions, including the striatum, hippocampus, cortex, midbrain, and thalamus (Bortolato et al, 2007; Hill et al, 2005b; Lomazzo et al, 2015; Wang et al, 2010) or changes in FAAH activity in any of these brain regions (Hill et al, 2008b). It is possible that the discrepancy of these effects could be related to the time point following the cessation of stress when AEA levels were measured; however, an alternate hypothesis is that there are differences between chronic homotypic and heterotypic stressors on CRH signaling. Chronic homotypic stress has been shown to elevate CRH mRNA in the amygdala (Gray et al, 2010), similar to what was seen with sustained exposure to corticosterone (Makino et al, 1994a,b; Swanson and Simmons, 1989), while CUS surprisingly has been found to have little effects on CRH in the amygdala (Kim et al, 2006; Sterrenburg et al, 2011) and actually downregulates CRHR1 in the amygdala (Sandi et al, 2008). As such, the divergence of the effects of homotypic vs heterotypic stress on AEA content could be due to the differential effects of these stress paradigms on $\mathrm{CRH}$ signaling; however, given that this relationship has only been established in the amygdala (Gray et al, 2015), this model cannot explain the differential effects 
in other brain regions. Regardless of the complexity of these findings, the general picture emerging from these studies is that AEA signaling is generally compromised, particularly within the amygdala and hippocampus, following exposure to stress.

\section{Effects of Acute Stress on 2-AG Brain Levels}

Unlike the effects of stress on AEA, the majority of studies suggest that stress acts to increase 2-AG signaling. Specifically, acute restraint stress produces moderate increases in 2-AG content within the mPFC (Hill et al, 2011b), hippocampus (Wang et al, 2012b) and hypothalamus (Evanson et al, 2010) while footshock increases 2-AG content in the periaqueductal gray (Hohmann et al, 2005). In contrast to these effects, several studies have shown that acute stress does not increase 2-AG content within the amygdala (Hill et al, 2009c; Patel et al, 2005b, 2009; Rademacher et al, 2008), at least at the time point analyzed immediately at the end of a 30-min restraint stress session. Unlike the rapid changes in AEA following stress, the increases in 2-AG show a prominent delay. Specifically, no changes in $2-A G$ content are evident in the $\mathrm{mPFC}$ after a 15 -min swim stress session or a 30-min bout of social defeat (Dubreucq et al, 2012; McLaughlin et al, 2012); increases in 2-AG, however, were detected in PFC $60 \mathrm{~min}$ following restraint stress (Hill et al, 2011b). These data indicate significant differences in the temporal dynamics of AEA and 2-AG changes following stress exposure. This time lag is consistent with several observations demonstrating that elevated corticosterone levels mediate the increase in 2-AG following stress. For example, the increase in 2-AG content both within the mPFC and hippocampus following stress is blocked by antagonism of the glucocorticoid receptor (Hill et al, 2011b; Wang et al, 2012b). Similarly, administration of corticosterone alone has been found to increase 2-AG content within the hippocampus (Atsak et al, 2012a) and hypothalamus (Di et al, 2005; Hill et al, 2010a), and corticosterone levels following stress correlate with 2-AG levels in the mPFC (Roberts et al, 2012). Given that it takes a minimum of $20 \mathrm{~min}$, and up to $60 \mathrm{~min}$, for corticosterone levels to elevate in the brain (Bouchez et al, 2012; Dominguez et al, 2014; Heinzmann et al, 2010), this temporal lag from stress onset corresponds with the delayed timeline for 2-AG content to increase. Collectively, these data indicate that corticosterone is the primary mediator of increased 2-AG release in response to stress; however, the mechanisms by which corticosterone enhances 2-AG levels are unresolved.

\section{Effects of Chronic Stress on 2-AG Brain Levels}

Similar to the mirroring effects of acute and repeated stress on AEA, the effects of chronic stress on 2-AG content are consistent, although more robust, than what is seen following acute stress. Also, similarly to AEA, the magnitude of these effects is very sensitive to whether the chronic stress is homotypic or heterotypic in nature. Chronic homotypic stress, including restraint and social defeat, reliably elevates 2-AG content in the amygdala (Hill et al, 2010b; Patel et al, 2005b, 2009; Rademacher et al, 2008), mPFC (Dubreucq et al, 2012; Patel et al, 2005b; Rademacher et al, 2008), hypothalamus (Dubreucq et al, 2012; Patel et al, 2004), and hippocampus (Dubreucq et al, 2012). Consistent with what was seen with AEA, the increased 2-AG content observed following chronic homotypic stress is largely recapitulated by exposure to chronic corticosterone in the hippocampus (Bowles et al, 2012), amygdala (Hill et al, 2005a; Gray et al, unpublished data), and mPFC (Gray et al, unpublished data). One report has demonstrated that chronic stress results in a reduction of MAGL expression at the membrane within the amygdala (where it would most efficiently metabolize 2-AG), suggesting that reduced hydrolysis may account for the increased 2-AG contents seen following chronic homotypic stress (Sumislawski et al, 2011). The increase in 2-AG following repeated stress is transient. We have demonstrated that, on the tenth day of exposure to restraint stress, 2-AG content in the amygdala is increased 20 min following stress onset and has returned to baseline by 60 min (Patel et al, 2009), where it remains at basal levels $24 \mathrm{~h}$ after the final stress (Hill et al, 2010b). These data would suggest that reductions in MAGL-mediated 2-AG hydrolysis likely account for the enhanced capacity of 2-AG signaling under conditions of chronic homotypic stress.

As with AEA, the effects of heterotypic stress on 2-AG content are less consistent. The only reliable finding to date is a reduction in 2-AG content within the hippocampus following CUS (Hill et al, 2005b; Lomazzo et al, 2015; Zhong et al, 2014). Asides from this, no studies have found any consistent changes in 2-AG content from chronic heterotypic stressors in any structures analyzed (Bortolato et al, 2007; Hill et al, 2005b, 2008b; Lomazzo et al, 2015; Wang et al, 2010). This variability may be a consequence of different time point for tissue collection after the final stress.

Taken together, these studies demonstrate a bidirectional effect of stress on the eCB system. In general, stress exposure reduces $\mathrm{AEA}$ and increases 2-AG levels throughout most brain regions examined. These effects appear to become amplified following chronic exposure to the same stressor, although chronic exposure to varying stressors seems to evoke less reliable changes in either of these molecules. Increases in $\mathrm{CRH}$ seem to be primarily responsible for the increased activity of FAAH and reduced levels of AEA within the amygdala, whereas elevations in corticosterone appear to be the primary mechanism by which stress increases 2-AG levels, at least within the mPFC and hippocampus (Figure 2).

\section{Effects of Acute and Chronic Stress on CB1 Receptors}

Few studies have examined the effects of acute stress on CB1 receptor levels. One report, looking at the binding site density of CB1 receptors in the amygdala, reported no effect of acute stress (Hill et al, 2009c). With the exception of the 


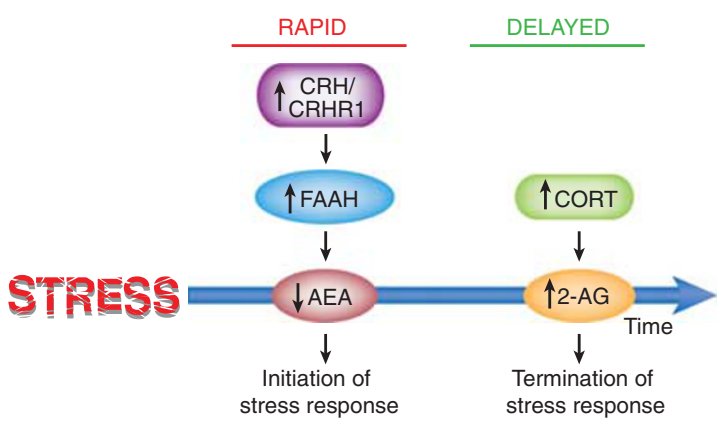

Figure 2. Temporal dynamics of anandamide (AEA) and 2-arachidonoyl glycerol (2-AG) changes following stress exposure. Acute exposure to stress rapidly increases corticotropin-releasing hormone $(\mathrm{CRH})$ signaling in the basolateral amygdala (BLA). The subsequent activation of CRHR1 receptors rapidly increases the enzymatic activity of fatty acid amide hydrolase (FAAH), resulting in a decrease of the inhibitory tone of AEA, which in turn contributes to the activation of hypothalamic-pituitaryadrenal (HPA) axis and stress-related behavioral responses. The delayed increase of brain corticosterone levels stimulates the release of 2-AG in the medial prefrontal cortex (MPFC) and paraventricular nucleus of hypothalamus (PVN). This increased 2-AG signaling at CB1 receptors contributes to negative-feedback inhibition of the HPA axis and termination of stress response.

PFC, chronic stress is associated with a downregulation of CB1 receptor expression. Using electrophysiology, mRNA, protein, and radioligand binding, downregulation of the CB1 receptor has been found in the hippocampus (Hill et al, 2005b, 2008b; Hu et al, 2011; Lee and Hill, 2013; Reich et al, 2009), hypothalamus (Hill et al, 2008b; Wamsteeker Cusulin et al, 2014; Wamsteeker et al, 2010), striatum (Hill et al, 2008b; Rossi et al, 2008, 2010; Wang et al, 2010), and dorsal root ganglion (Hong et al, 2011) following exposure to an array of both chronic homotypic and heterotypic stressors. The amygdala appears to be somewhat resistant to these effects as many reports have demonstrated no effect of chronic stress on $\mathrm{CB} 1$ expression using radioligand binding (Hill et al, 2008b; Lee and Hill, 2013); at the electrophysiological level, however, chronic homotypic stress has been shown to desensitize CB1 receptors in the BLA, at least on GABAergic terminals (Patel et al, 2009). As with many of the central effects of stress, several reports have demonstrated that this downregulation of $\mathrm{CB} 1$ receptor expression or signaling is reversed following a period of recovery (Lee and Hill, 2013; Rossi et al, 2008; Wamsteeker et al, 2010). There is strong evidence that these effects are mediated by corticosterone as chronic administration of corticosterone can recapitulate the stress-induced downregulation of the CB1 receptor (Bowles et al, 2012; Hill et al, 2008a; Hong et al, 2011; Rossi et al, 2008); additionally, blockade of the glucocorticoid receptor abrogates the effects of stress on the CB1 receptor (Hong et al, 2011; Rossi et al, 2008; Wamsteeker et al, 2010).

As mentioned, the $\mathrm{MPFC}$ is one region in the brain where both chronic homotypic and heterotypic stressors have reliably been found to increase the expression of the CB1 receptor at the mRNA-, protein-, and receptor-binding level
(Bortolato et al, 2007; Hill et al, 2008b; Lee and Hill, 2013; McLaughlin et al, 2013; Zoppi et al, 2011). The mechanism responsible for the discrepancy in the $\mathrm{MPFC}$ (in comparison to other brain regions) is not clear but should be a topic of further research.

Taken together, this vast body of data present several common themes that could be relevant to stress neurobiology and will be the focus of the following sections. First, acute exposure to stress results in a relatively rapid decline of AEA signaling within the amygdala and hippocampus, which is likely mediated by an increase in CRH signaling at the CRHR1. The subsequent release of corticosterone following stress results in a delayed elevation in 2-AG, and possibly AEA, through several corticolimbic structures. Second, in response to chronic homotypic stress, there is a clear depletion of AEA and an elevation of 2-AG throughout the forebrain. These effects mirror what is seen with acute stress but appear to be amplified. Interestingly, chronic heterotypic stress exerts less reliable changes in either AEA or 2-AG. It is unclear whether this is due to differences in measurement of time points following the cessation of stress, the stress induction protocols used, or different brain areas examined. Finally, regardless of the modality, both chronic homotypic and heterotypic stress cause a significant decrease in CB1 receptor expression throughout all subcortical structures examined, but an increase in $\mathrm{CB} 1$ receptor expression in the mPFC. Collectively, these data indicate that the eCB system is exquisitely sensitive to stress exposure and exhibits dynamic and temporally specific changes in response to stressful stimuli.

\section{Functional Role of eCB Signaling in the Neurobiological Effects of Stress}

Role of eCBs in stress-induced regulation of the HPA axis. There is substantial evidence that $\mathrm{eCB}$ signaling regulates the HPA axis and this topic has been addressed in significant depth in previous reviews (Hill and Tasker, 2012; Steiner and Wotjak, 2008). As mentioned above, disruption of $\mathrm{eCB}$ signaling recapitulates many of the effects of stress, including activation of the HPA axis; the interpretation of these data would suggest that there is an $\mathrm{eCB}$ tone that actively functions to constrain activation of the HPA axis. Specifically, acute administration of a $\mathrm{CB} 1$ receptor antagonist results in an increase in basal induction of c-fos within the PVN, and an elevation in circulating levels of ACTH and/or corticosterone (Atkinson et al, 2010; Doyon et al, 2006; Ginsberg et al, 2010; Hill et al, 2010b; Manzanares et al, 1999; Newsom et al, 2012; Patel et al, 2004; Roberts et al, 2014; Steiner et al, 2008; Wade et al, 2006). The neuroanatomical site of action for this 'gatekeeper' role of $\mathrm{eCB}$ signaling on HPA output suggests an important role for the BLA. Specifically, local microinjections of CB1 receptor antagonists into the PVN (Evanson et al, 2010) or the mPFC (Hill et al, 2011b) have found no effect on basal corticosterone levels, but local administration of a CB1 receptor antagonist into the BLA is sufficient to increase HPA axis 
activity (Ganon-Elazar and Akirav, 2009; Hill et al, 2009c). This suggests that the BLA may be an important site for eCB-mediated control of the HPA axis, although it is likely that there are potentially multiple redundant sites whereby $\mathrm{eCB}$ signaling exerts some effect on HPA axis function.

Interestingly, as described above, exposure to stress causes a rapid, CRH-mediated reduction in AEA content within the amygdala (Gray et al, 2015; Hill et al, 2009c; Patel et al, 2005b; Rademacher et al, 2008). As AEA is believed to represent the 'tonic' signal of the HPA axis, these data bring about the intriguing hypothesis that, under steady-state conditions, there is an AEA tone within the BLA, and possibly other areas, that functions to constrain the HPA axis under non-stressful conditions, and in response to stress this tone is disrupted, facilitating stress-induced activation of the HPA axis. Consistent with this hypothesis, acute administration of a CB1 receptor antagonist evokes a limited and specific pattern of neuronal activation in the brain, of which the BLA is one of the most prominent sites of activity, in addition to the PVN (Newsom et al, 2012; Patel et al, 2005a; Singh et al, 2004). More so, global or intra-BLA inhibition of AEA-hydrolysis dampens stress-induced activation of the HPA axis (Bedse et al, 2014; Hill et al, 2009c; Patel et al, 2004). In fact, the ability of systemic administration of a FAAH inhibitor to dampen neuronal activation within the $\mathrm{PVN}$ is completely reversible by local $\mathrm{CB} 1$ receptor antagonism within the BLA (Bedse et al, 2014), indicating that elevations of AEA signaling within the BLA are capable of attenuating stress-induced activation of the HPA axis, likely through a trans-synaptic relay from the BLA to the PVN. As such, these data would indicate that AEA is a regulatory signal within the BLA that suppresses activation of the HPA axis by gating BLA to PVN communication. Additionally, the rapid loss of AEA signaling within the BLA, through a CRHR1-mediated induction of FAAH activity, may represent an endogenous mechanism that regulates the magnitude of the HPA axis response to stress (Gray et al, 2015). Collectively, these data indicate that the BLA is an important modulatory seat for the effects of AEA signaling on the initiation of stress-induced activation of the HPA axis.

In addition to this gatekeeper role for the initial activation of the HPA axis in response to stress, there is also substantial evidence that an increase in 'phasic' eCB signaling contributes to limiting the magnitude and promoting the termination of stress-induced HPA axis activity. For example, acute administration of a CB1 receptor antagonist enhances neuronal activation within the PVN in response to stress and potentiates the magnitude and duration of stressinduced corticosterone secretion (Hill et al, 2011b; Newsom et al, 2012; Patel et al, 2004; Roberts et al, 2014). As 2-AG is believed to represent the 'phasic' signal of the eCB system, these data would suggest that stress-induced elevations in 2AG content in the mPFC and hypothalamus (Evanson et al, 2010; Hill et al, 2011b), which are known to be important for glucocorticoid negative feedback on the HPA axis (Dallman, 2005; Diorio et al, 1993), contribute to termination of the stress response. Specifically, local administration of a CB1 receptor antagonist into the PVN impairs glucocorticoidmediated rapid feedback inhibition of the HPA axis (Evanson et al, 2010), while blockade of CB1 receptors within the mPFC impairs normative recovery of the HPA axis following cessation of stress (Hill et al, 2011b). These findings are consistent with the ability of glucocorticoids to elevate eCB content (Atsak et al, 2012a; Di et al, 2005; Hill et al, 2010a) and suggest that $\mathrm{eCB}$ signaling is a necessary component of glucocorticoid-mediated negative feedback in the brain. As glucocorticoid receptors are predominantly localized in the somatodendritic region of postsynaptic cells (Johnson et al, 2005; Liposits and Bohn, 1993), our current working hypothesis is that glucocorticoids mobilize 2-AG to suppress excitatory inputs activated by exposure to stress and facilitate recovery to basal levels of activity.

In addition to their role in the termination of acute stressinduced activation of the HPA axis, there is also evidence that the progressive recruitment of 2-AG signaling during chronic homotypic stress contributes to adaptation of the HPA axis. Specifically, in adults, repeated exposure to the same stressor results in habituation of the HPA axis response, such that the magnitude of corticosterone release to stress exposure decreases over time (Grissom and Bhatnagar, 2009). As discussed above, this same stress regimen that promotes HPA axis habituation concomitantly results in elevations in 2-AG content throughout the forebrain (Dubreucq et al, 2012; Hill et al, 2010b; Patel et al, 2005b). Interestingly, acute administration of a CB1 receptor antagonist to animals before the final presentation of a repeated stressor effectively 'dishabituates' the animals such that dramatic elevations in neuronal activation throughout stress regulatory circuits are observed, such as in the BLA and PVN, and significant increases in corticosterone occur, relative to habituated animals (Hill et al, 2010b; Patel et al, 2005b). These data have led to the hypothetical model that eCB signaling is essential for stress adaptation and that the active recruitment of 2-AG signaling during repeated stress dampens neural circuits activated by stress, thereby resulting in a systems-level habituation to stress (Hill et al, 2010b; Patel and Hillard, 2008).

Collectively, these data highlight several important roles of the eCB system in the regulation of the HPA axis. First, tonic AEA signaling within the BLA gates HPA axis activity, and disruption of this AEA tone by stress (or through pharmacological/genetic means) results in the activation of the HPA axis and the secretion of corticosterone. Second, the increased levels of corticosterone following the launch of the stress response enhance 2-AG signaling in the $\mathrm{mPFC}$ and PVN; this may contribute to negative-feedback inhibition of the HPA axis and termination of the stress response. Third, upon repeated presentation of a common stressor, 2-AG levels are progressively enhanced within forebrain circuits and may mediate adaptation to stress and habituation of the HPA axis. As such, the eCB system is both a regulator and a target of stress-induced activation of the HPA axis.

Role of eCBs in stress-induced anxiety. A central theme that has emerged over the past decade is that eCBs have a 
prominent role in the regulation of behavioral processes during times of stress or environmental challenge. Similarly to the regulation of HPA axis function described above, eCBs appear to reduce behavioral signs of anxiety specifically under stressful, aversive, or environmentally challenging conditions. For example, while pharmacological or genetic disruption of CB1 receptor signaling can moderately increase anxiety under basal conditions (Haller et al, 2002, 2004; Hill et al, 2011a; Martin et al, 2002; Mikics et al, 2009; Uriguen et al, 2004), this manipulation dramatically enhances anxiety induced by stress or environmental aversiveness (Gamble-George et al, 2013; Haller et al, 2004; Hill et al, 2011a). These data would suggest that dynamic changes in eCB signaling in response to stress may contribute to fluctuations in anxiety-like behavior, and subsequent work targeting AEA and 2-AG signaling independently has helped shed light on the potential mechanisms by which this process occurs.

The putative role of AEA in regulating anxiety was first highlighted by the Piomelli laboratory, who demonstrated that inhibition of AEA-hydrolysis by FAAH resulted in a reduction of anxiety (Kathuria et al, 2003). This ability of AEA signaling to reduce anxiety was then determined to be highly specific to the stressful nature of the environmental context such that inhibition of FAAH, through both pharmacological and genetic means, is more effective at reducing anxiety-related behaviors under challenging environmental conditions or after overt stressor exposure (Bluett et al, 2014; Dincheva et al, 2015; Haller et al, 2009; Hill et al, 2013b; Naidu et al, 2007). One potential interpretation of these data is that stress or aversive experiences produce anxiety through a rapid reduction in AEA signaling, which results in a transient decline in CB1 receptor signaling that facilitates the emergence of an anxiety state. These data are consistent with the aforementioned effects of CB1 receptor blockade on anxiety, as well as the fact that stress can rapidly reduce AEA content in anxiety-regulating circuits, such as the amygdala and hippocampus. Consistent with this model, we have demonstrated that stress-induced release of CRH rapidly triggers FAAH activity in the BLA to reduce AEA signaling, which in turn promotes the generation of anxiety (Gray et al, 2015). Importantly, central AEA levels are negatively correlated with anxiety-like behaviors (Bluett et al, 2014), and elevating AEA signaling can effectively curb anxiety induced by both acute and chronic stress (Bluett et al, 2014; Campos et al, 2010; Hill et al, 2013b; Lomazzo et al, 2015; Rossi et al, 2010). As such, it has been proposed that AEA may function as a mediator of 'emotional homeostasis' (Haller et al, 2013; Marco and Viveros, 2009), functioning to keep anxiety at bay in resting conditions, from which disruption of this signal by stress could contribute to the generation of an anxious state (Gunduz-Cinar et al, 2013a). There is evidence indicating that the neuroanatomical circuits mediating these effects are likely broad and diffuse. The ability of $\mathrm{CRH}$ signaling to trigger FAAH activity in the BLA has been explicitly linked to the generation of anxiety (Gray et al, 2015), but local overexpression of FAAH within the mPFC (creating a state of AEA deficiency) has also been found to be sufficient to induce anxiety, suggesting that this site may also be an important seat of the effects of AEA on anxiety control (Rubino et al, 2008). Finally, an additional report has found that administration of the AEA transport and metabolism inhibitor AM404 into the ventral hippocampus can reverse stress-induced anxiety (Campos et al, 2010). Given that brain-wide reductions in AEA correlate with anxiety following stress (Bluett et al, 2014), it is quite likely that while dynamic changes in AEA signaling within a discrete region may be capable of modulating anxiety, a systems-level shift in AEA signaling across many forebrain structures is likely relevant for contributing to stress-induced anxiety.

More recently, a role for 2-AG signaling in the regulation of anxiety has been examined using genetic and pharmacological approaches. Similar to the effects seen with CB1 receptor blockade, treatment with a MAGL inhibitor (to inhibit 2-AG metabolism) reduces basal anxiety in some studies but seems to particularly reduce anxiety under highstress testing conditions (Aliczki et al, 2012, 2013; BusquetsGarcia et al, 2011; Kinsey et al, 2011; Sciolino et al, 2011). Given that stress can increase 2-AG release, one interpretation of these data would be that the mobilization of 2-AG acts to buffer against stress-induced anxiety and that augmentation of this signal through the inhibition of MAGL potentiates this effect. Consistent with this, central genetic 2-AG deficiency results in increased anxiety that can be reversed by acute normalization of 2-AG levels (Shonesy et al, 2014). There is also evidence that potentiation of $2-A G$ signaling can dampen anxiety induced by chronic stress (Sumislawski et al, 2011; Zhang et al, 2015; but see Lomazzo et al, 2015 for negative findings). These studies clearly support the notion that 2-AG also has a key role in regulating anxiety and stress responsivity. Interestingly, unlike AEA where these effects are all $\mathrm{CB} 1$ receptor dependent, in the case of 2-AG augmentation, both $\mathrm{CB} 1$ and $\mathrm{CB} 2$ receptors have been implicated; however, evidence supporting a CB1dependent effect are stronger (Busquets-Garcia et al, 2011; Kinsey et al, 2011; Sciolino et al, 2011; Sumislawski et al, 2011).

Collectively, these data indicate that elevating both AEA and 2-AG signaling attenuates stress-induced anxiety, although the mechanisms of these effects may be different, especially as their dynamic regulation by stress occurs in a bidirectional manner. Although site-specific studies have identified the amygdala, mPFC, and hippocampus as potential substrates for the effects of AEA signaling on stress-induced anxiety, no work to date has identified the circuits through which 2-AG exerts its effects, although it seems reasonable to predict that overlapping populations of CB1 receptors are involved in both of these processes. Consistent with this hypothesis, emerging data strongly implicate CB1 receptors expressed on forebrain glutamatergic neurons as critical for the anxiolytic effects of eCBs, while $\mathrm{CB} 1$ receptors on GABAergic terminals do not appear to be involved in these anxiolytic effects (Rey et al, 2012; Rossi 
et al, 2010; Ruehle et al, 2013). Additionally, a recent report has also indicated that $\mathrm{CB} 1$ receptors on serotonergic neurons may also be important for the regulation of anxiety (Dubreucq et al, 2012). Future work will require combined genetic and neuroanatomical approaches to clearly define the circuits by which eCB signaling regulates stress-induced anxiety.

Role of eCBs in stress-induced modulation of memory function. Stress- and emotional arousal-activated neurobiological systems have a highly adaptive role in ensuring that the strength of our memories will reflect their emotional significance (McGaugh, 2015). Although discussed in greater depth in these comprehensive reviews (Joels et al, 2011; Rodrigues et al, 2009; Roozendaal et al, 2009), in brief, stress and glucocorticoids typically facilitate learning performances (Akirav et al, 2004; Salehi et al, 2010) and enhance memory consolidation (de Kloet et al, 1999; Joels and Baram, 2009; Oitzl and de Kloet, 1992; Roozendaal, 2000; Sandi and Rose, 1994). Particularly, the BLA appears to have a crucial role in mediating the glucocorticoid-enhancing effects on memory consolidation (Roozendaal and McGaugh, 1996,1997). In contrast, stress and glucocorticoids impair memory retrieval during emotionally arousing tests both in animals (de Quervain et al, 1998) and human subjects (Bentz et al, 2013; de Quervain et al, 2009). In this section, we will discuss basic research findings of how the eCB system modulates stress effects on memory, although these have been reviewed in greater depth elsewhere (Atsak et al, 2012b; Morena and Campolongo, 2014a). Similar to what has been found with anxiety, the degree of stressfulness or aversiveness seems to contribute to the ability of $\mathrm{eCB}$ signaling to influence memory processes. With respect to memory acquisition, Campolongo et al (2012) showed that systemic injection of the AEA transport inhibitor AM404 impaired the acquisition of the novel object recognition task only in rats tested under higher stressful condition (ie, not handled and tested under bright light in an empty arena), without altering memory performance of rats tested under lower stressful condition (ie, extensively handled and tested under dim red light in an arena with familiar bedding (Campolongo et al, 2012).

However, local infusions into discrete brain regions have given different results. Tan et al (2011) reported that blockade of CB1 receptor activity in the BLA prevented the acquisition of associative fear memory when an olfactory cue was associated with a suprathreshold footshock intensity $(0.8 \mathrm{~mA})$ in a fear conditioning paradigm (Tan et al, 2011). Further, intra-BLA administration of AM404 strongly potentiated fear memory acquisition when the behavioral task was performed with a lower subthreshold footshock intensity $(0.4 \mathrm{~mA})$ that did not produce an associative freezing response in control rats at testing (Tan et al, 2011). These data would suggest that eCB signaling becomes recruited during highly aversive situations and under these conditions may act to impair or potentiate memory acquisition depending on the nature and intensity of the environmental stimuli, on the type of memory, and brain region involved.

Interestingly, with respect to memory consolidation, it appears more so that $\mathrm{eCB}$ signaling is important for the facilitation of consolidation that occurs in highly arousing situations. For example, intra-BLA blockade of eCB transmission dose-dependently disrupts memory consolidation in an inhibitory avoidance task (Campolongo et al, 2009). Consistent with this finding, others have reported that infusion of the CB1 receptor antagonist AM251 into the amygdala (Bucherelli et al, 2006) or hippocampus (de Oliveira Alvares et al, 2005) disrupts the consolidation of long-term memory, possibly by inhibiting long-term potentiation (LTP; de Oliveira Alvares et al, 2006). Again, it is likely that the level of stress elicited by the behavioral task results in differential engagement of eCBs to modulate memory consolidation. In support of this view are observations that rats trained in an inhibitory avoidance task with a higher footshock intensity $(0.45 \mathrm{~mA})$ present better memory retention than rats trained with a lower footshock intensity $(0.35 \mathrm{~mA})$, and this effect is paralleled by an increase in AEA levels within the amygdala, hippocampus, and $\mathrm{mPFC}$ (Morena et al, 2014b). Further, AEA has a crucial role in potentiating memory consolidation via $\mathrm{CB} 1$ receptor activation in these cortico-limbic circuits (Morena et al, 2014b). Similarly, de Oliveira Alvares et al (2010) found that a strong emotionally arousing experience is a necessary condition for the involvement of the hippocampal eCB system on memory consolidation. In this study, intra-hippocampal infusion of AM251 impaired the consolidation of a strong conditioning training $(0.7 \mathrm{~mA}$ footshock intensity), but it did not induce any effect on a weak fear conditioning paradigm $(0.3 \mathrm{~mA}$ footshock intensity; (de Oliveira Alvares et al, 2010). Thus it appears that a certain degree of emotional arousal leads to an optimal activation of stress mediators that is necessary for the eCB system to mediate the formation of a strong memory trace. Unlike what was seen with more moderate stressors, such as restraint, where AEA becomes reduced, in these highly arousing situations there actually appears to be an increase in AEA, which then contributes to the consolidation of these emotionally salient memories.

The importance of the eCB system in facilitating the extinction of emotionally aversive memories has also been consistently reported by several groups. Over a decade ago, Marsicano et al (2002) and subsequent investigators demonstrated that genetic deletion of CB1 receptors, as well as systemic or intra-BLA inhibition of eCB transmission, robustly inhibits fear extinction (Chhatwal et al, 2005; Ganon-Elazar and Akirav, 2009; Marsicano et al, 2002; Suzuki et al, 2004). Tone presentation during extinction trials results in elevated levels of eCBs in the BLA (Gunduz-Cinar et al, 2013b; Marsicano et al, 2002). Chhatwal et al (2005) and others demonstrated that intraperitoneal or intracerebroventricular injection of AM404 enhances fear extinction via a CB1-dependent mechanism (Bitencourt et al, 2008; Chhatwal et al, 2005; Pamplona et al, 2008). A more recent study underlined the importance of the BLA in these AEA 
facilitating effects on memory extinction. Gunduz-Cinar et al, 2013b found that intra-BLA infusions of the FAAH inhibitor AM3506 potentiate memory extinction through the activation of CB1 receptors (Gunduz-Cinar et al, 2013b). Thus the evidence obtained to date strongly suggests that the activation of the $\mathrm{eCB}$ system represents an important step for the facilitation of emotionally aversive memory extinction to occur (Gunduz-Cinar et al, 2013a).

It has become apparent that glucocorticoids are an important mechanism of how the $\mathrm{eCB}$ system becomes engaged by stress to modulate memory processes. As mentioned, glucocorticoid administration selectively enhances the consolidation of emotionally arousing experiences within the BLA (Roozendaal and McGaugh, 1996, 1997). Campolongo et al (2009) provided the first evidence that this mechanism is mediated by the amygdalar eCB system. They found that intra-BLA administration of a non-impairing dose of the CB1 receptor antagonist AM251 after inhibitory avoidance training blocked the memory-enhancing effects induced by systemic injection of corticosterone, suggesting that glucocorticoids recruit eCB signaling within the BLA to enhance memory consolidation (Campolongo et al, 2009). Similarly, a separate study reported that a CB1 receptor antagonist infused into the hippocampus blocked the memory enhancement induced by the synthetic glucocorticoid dexamethasone (de Oliveira Alvares et al, 2010). Atsak et al (2014) have recently shown that these glucocorticoid effects on the eCB system, within the BLA, are dependent on a membrane glucocorticoid receptor, thus involving a rapid non-genomic mechanism (Atsak et al, 2014). Furthermore, they found that $\mathrm{eCB}$ signaling was also required for glucocorticoids to induce an increase in CREB phosphorylation in BLA pyramidal neurons (Atsak et al, 2014). A similar model has also been proposed for glucocorticoid-impairing effects on memory retrieval. Indeed, systemic administration of corticosterone $1 \mathrm{~h}$ before retention testing, by increasing hippocampal 2-AG levels, impairs the retrieval of a contextual fear memory; an effect which is reversible by pharmacological blockade of hippocampal CB1 receptors (Atsak et al, 2012a). In line with these findings, the ability of glucocorticoids to enhance the extinction of emotionally aversive memories is also dependent on CB1 receptors and can be replicated by administration of AM404 (Bitencourt et al, 2014). These effects are all consistent with data indicating that glucocorticoids increase AEA and/or 2-AG content within the amygdala and hippocampus (Atsak et al, 2012a; Hill et al, 2010a). Mechanistically, these data would suggest that $\mathrm{eCB}$ signaling is downstream of glucocorticoids, and more so $\mathrm{eCB}$ signaling mediates the effects of glucocorticoids on the modulation of memory processes. Interestingly, at least with respect to consolidation, the role of eCB signaling, while downstream of glucocorticoids, is upstream of norepinephrine, as modulation of eCB signaling did not block the effects of beta-adrenoreceptor activation on enhancing memory consolidation (Atsak et al, 2014). More so, FAAH inhibition has been found to increase norepinephrine levels within the amygdala in response to stress
(Bedse et al, 2014), suggesting that the effects of eCB signaling are upstream of norepinephrine release. Collectively, these findings suggest that glucocorticoids rapidly recruit eCBs in the BLA to increase the sensitivity of pyramidal neurons to the memory-enhancing effects of norepinephrine (McIntyre et al, 2002; Quirarte et al, 1997). The evidence summarized above clearly indicates that the eCB system modulates cognitive function in a manner dependent on the aversiveness of the environmental condition and on the degree of emotional arousal at the time of testing.

Role of eCBs in stress-induced regulation of pain. With respect to acute stress, there is evidence that an increase in $\mathrm{eCB}$ signaling contributes to non-opioid stress-induced analgesia (Hu et al, 2014). The initial demonstration of this effect found that CB1 receptor-deficient mice did not exhibit antinociception following exposure to swim stress (Valverde et al, 2000). Following on this finding, Hohmann et al (2005) presented a highly comprehensive characterization of the role of eCB signaling in non-opioid stress-induced analgesia. Specifically, they demonstrated that exposure to footshock elevated both AEA and 2-AG within the periaqueductal gray and that blockade of $\mathrm{CB} 1$ receptors in this region prevented footshock stress-induced analgesia (Hohmann et al, 2005). These results have been extended by reports demonstrating that analgesia occurring after exposure to the context of footshock similarly involves an $\mathrm{eCB}$ mechanism in the periaqueductal gray (Olango et al, 2012). More so, these results have been extended by other reports that global disruption of CB1 receptor signaling block stress-induced analgesia (Kurrikoff et al, 2008), as well as a recent report that eCB signaling similarly mediates stress-induced analgesia in fish (Wolkers et al, 2015). As such, there seems to be substantial evidence that stress-induced increases in $\mathrm{eCB}$ signaling mediate the acute analgesic effect that occurs after exposure to stress. In addition to these effects, one recent report demonstrated that chronic inhibition of FAAH, but not MAGL, is capable of reversing the development of hyperalgesia after exposure to chronic stress (Lomazzo et al, 2015), suggesting the possibility that reductions in AEA signaling, which occur following chronic stress, may contribute to the development of hyperalgesia. As such, the current data do suggest that dynamic changes in eCB signaling from acute and chronic stress may differentially contribute to changes in pain sensitivity.

Role of eCBs in stress-induced regulation of reward. There are two domains within reward processes in which changes in eCB signaling from stress could be relevant. First, stress exposure is known to be a precipitating factor in drug use and relapse (Koob et al, 2014). With respect to eCB signaling, there are data that suggest the possibility that $\mathrm{eCB}$ signaling may be involved in this process. For example, CB1 receptordeficient mice have been found to be resistant to elevations in alcohol consumption in response to footshock (Racz et al, 2003); however, acute CB1 receptor antagonism did not 
prevent alcohol reinstatement in response to footshock stress (Economidou et al, 2006). Without further evidence to help resolve this discrepancy, one interpretation could be that eCB signaling contributes to stress-induced alcohol consumption but not stress-induced relapse following cessation. Similar discrepancies have been found with cocaine whereby CB1 receptor antagonism does not block footshock-induced reinstatement of cocaine-seeking behavior (De Vries et al, 2001; Kupferschmidt et al, 2012) but has been found to reverse the reinstatement of cocaine-seeking behavior in response to swim stress (Vaughn et al, 2012) or direct administration of CRH (Kupferschmidt et al, 2012). Here it is possible that the stress modality itself could have differential effects on eCB signaling (as discussed above) in which eCB signaling could be important for some forms of stress-induced cocaine reinstatement, while it is dispensable for others. More work, particularly in the context of discrete neural circuit manipulations, is required to fully understand the contributions $\mathrm{eCB}$ signaling has with respect to stressinduced drug use and relapse.

The second domain of reward processing where the $\mathrm{eCB}$ system may be relevant for the effects of stress is the development of impairments to reward sensitivity (or 'anhedonia') that develop following exposure to chronic stress. Specifically, animal studies have reliably demonstrated that exposure to chronic stress can produce anhedonia, as gauged by the preference or consumption of sucrose. Interestingly, chronic administration of a FAAH inhibitor during chronic stress has been shown to counter the development of anhedonia (Bortolato et al, 2007; Rademacher and Hillard, 2007), suggesting that the deficiency in AEA signaling that emerges from chronic stress may render reward circuits less sensitive and promote the development of anhedonia. Alternately, both genetic (Martin et al, 2002) or pharmacological (Rademacher and Hillard, 2007) disruption of CB1 receptor signaling can significantly potentiate and accelerate the development of anhedonia in response to chronic stress. This would suggest that potential increases in 2-AG signaling that occur following chronic stress could be a protective mechanism that is elevating in an attempt to buffer against the development of anhedonia following chronic stress. Consistent with this, it has also been found that chronic administration of a MAGL inhibitor during chronic stress can counter the development of anhedonia (Zhong et al, 2014). Very reminiscent of what is seen following exposure to stress, chronic intermittent alcohol consumption increases striatal 2-AG levels leading to a compensatory reduction of $\mathrm{CB} 1$ receptor functionality and a loss of CB1-mediated synaptic plasticity in the lateral part of the dorsal striatum (DePoy et al, 2013). Future work is required to determine whether this rearrangement of the eCB system by chronic alcohol contributes to changes in emotional behavior or stress sensitivity.

Role of eCBs in stress-induced synaptic plasticity. A common theme that has emerged from this review is that eCB signaling is recruited or modulated by stress mediators, such as glucocorticoids or $\mathrm{CRH}$, to modulate a physiological output, such as anxiety or memory. At a mechanistic level, eCBs likely modulate these processes by impacting a range of eCB-mediated synaptic plasticity mechanisms. Retrograde eCB signaling mediates multiple forms of synaptic plasticity, such as long-term depression (LTD) or depolarizationinduced suppression of inhibition/excitation (DSI/E). Recently, the effects of stress on synaptic transmission and plasticity have become a growing area of research (reviewed in (Joels et al, 2009; Popoli et al, 2011; Senst and Bains, 2014; Bains et al, 2015). As discussed, the CB1 receptor is expressed throughout the brain and is present on glutamate and GABA synapses in stress-sensitive circuits, such as the hypothalamus, mPFC, hippocampus, and amygdala. This includes CB1 receptor expression on inputs to critically stress-sensitive regions, including the BLA (Azad et al, 2003; Huang et al, 2003; Yoshida et al, 2011) and CeA (Kamprath et al, 2011; Ramikie et al, 2014; Roberto et al, 2010) neurons, which regulate motivational, affective, and autonomic responses to stress, as well as parvocellular neurosecretory cells (PNCs) in the PVN that regulate the release of CRH to promote activation of the HPA axis (Herkenham et al, 1990; Wittmann et al, 2007). The eCB system is extremely labile in response to stress and this has a profound impact on both short-term and long-term plasticity at synapses, particularly in the hypothalamus.

In the PVN, eCB synthesis can be driven by glucocorticoids; this results in a presynaptic decrease in glutamate release (Di et al, 2003; Wamsteeker et al, 2010), which contributes to dampening HPA axis activity following stress (Evanson et al, 2010). Why these effects are not observed at GABA synapses, which express CB1 receptors is something that requires further investigation, but does suggest a level of specificity with respect to which synapses are targeted by glucocorticoid-eCB interactions. Consistent with these in vitro effects, activation of the HPA axis in vivo can also impact eCB signaling in the hypothalamus. In response to acute stress, eCB signaling is positively modulated in a corticosterone-dependent manner as evidenced by an increase $\mathrm{eCB}$ signaling at both glutamate and GABA synapses (Wamsteeker et al, 2010). This phenomenon of glucocorticoid regulation of synaptic function through an eCB mechanism has been found to be a widespread phenomenon throughout most of the brain. Within the hippocampus (Wang et al, 2012b) and mPFC (Hill et al, $2011 b$ ), in vitro administration of corticosterone or in vivo exposure to stress can enhance eCB-mediated suppression of GABAergic transmission in a glucocorticoid receptordependent manner. Similarly, within the dorsal raphe, glucocorticoids can rapidly suppress glutamate release through an $\mathrm{eCB}$ mechanism; whether this mechanism also applies to GABAergic synapses remains to be explored (Wang et al, 2012a). The effects of glucocorticoids within the amygdala, however, seem to be different than what is seen in these other regions. In the BLA, both in vivo exposure to stress or in vitro application of corticosterone result in an increase, not a decrease, in glutamate currents through a 
mineralocorticoid receptor-dependent process (Karst et al, 2010). However, the application of corticosterone to a BLA slice from an animal that has been exposed to stress results in a suppression of glutamate release, which is mediated by the release of eCBs (Karst et al, 2010). This would suggest that stress initially primes the BLA through an increase in excitatory transmission; once corticosterone is released in response to stress, it reduces excitation of the BLA, through an $\mathrm{eCB}$ mechanism, leading to an attenuation of amygdala activity. The temporal pattern of these processes mirrors the rapid decline (through $\mathrm{CRH}$ ) and subsequent increase (through corticosterone) of AEA dynamics within the amygdala, suggesting the possibility that regulation of glutamatergic transmission could be the mechanism by which fluctuations in AEA contribute to the initiation and termination of stress-induced anxiety.

In addition to the importance of $\mathrm{eCB}$ signaling in mediating synaptic changes from glucocorticoids, there is also evidence that exposure to stress itself may actually influence the functionality of CB1 receptors. Specifically, studies examining the effects of CB1 stimulation in the BNST have shown that exposure to stress causes a switch in the effects on $\mathrm{CB} 1$ receptor stimulation on neuronal firing. Rather than promoting LTD, CB1 receptor activation after stress promotes LTP (Glangetas et al, 2013). Consistent with this switch in functionality, it has also been reported that the application of a CB1 receptor agonist to hippocampal slices from stressed animals switches CB1 receptor activation from suppressing glutamatergic transmission to enhancing LTP (Reich et al, 2013). The mechanisms behind this ability of CB1 signaling to switch from inhibitory to excitatory have not been explored but may explain the interactive effects of stress and cannabinoids on causing opposite responses to those typically seen in non-stressed animals (Fokos and Panagis, 2010; Hill and Gorzalka, 2004; Patel et al, 2005a).

As discussed previously, there is significant evidence that chronic exposure to stress compromises CB1 receptor expression and signaling at the synaptic level. For example, repeated homotypic stress causes a progressive loss of eCB signaling at both glutamate and GABA synapses in the PVN (Wamsteeker et al, 2010). Consistent with this phenomenon, chronic stress-induced decreases in CB1 receptor regulation of GABAergic transmission has also been reported in the striatum (Rossi et al, 2008), amygdala (Patel et al, 2009), and hippocampus (Hu et al, 2011), and a loss of CB1 regulation of glutamatergic transmission has been found in the nucleus accumbens (Wang et al, 2010) and dorsal raphe (HajDahmane and Shen, 2014), suggesting that a loss of presynaptic CB1 receptor functionality may be a general feature in regions that gate stress responses. Consistent with this, eCB-mediated forms of synaptic plasticity have also been found to become impaired following chronic stress, such as DSE and LTD in the nucleus accumbens (Wang et al, 2010), as well as DSI (Zhong et al, 2014) and LTP in the hippocampus (Zhang et al, 2015). Quite surprisingly, the amygdala, again, seems to be the one brain region that shows different effects under conditions of chronic stress. Despite exhibiting desensitization of $\mathrm{CB} 1$ receptors on GABA terminals within the BLA following chronic stress (Patel et al, 2009), repeated exposure to restraint stress actually increases both DSI (Patel et al, 2009) and inhibitory LTD (Sumislawski et al, 2011) in the BLA. The interpretation of these data are that, despite desensitization of the CB1 receptor on GABAergic terminals, the enhancement of 2-AG signaling produced by chronic homotypic stress overcomes this reduced receptor sensitivity to produce enhanced forms of synaptic plasticity. It is not clear why the effects of enhanced 2-AG are only apparent within the amygdala but may relate to the potential sensitivity of 2-AG signaling in the amygdala to repeated stress (Hill et al, 2010b). These findings are not surprising in some regards, though, given that the amygdala has often been found to exhibit differential effects to chronic stress than many other brain structures (McEwen, 2012b).

The loss of CB1 receptors from chronic stress is likely due to activation of genomic glucocorticoid receptors that trigger a loss of functional presynaptic $\mathrm{CB} 1$ receptors, as the effect is blocked by the glucocorticoid receptor antagonist RU486 (Rossi et al, 2008; Wamsteeker et al, 2010). The mechanisms through which glucocorticoid receptor activation translates into a downregulation of $\mathrm{CB} 1$ receptors remain unresolved, although it is likely due to either direct negative regulation of the CB1 receptor gene by glucocorticoids (as has been demonstrated in the striatum; (Mailleux and Vanderhaeghen, 1993) or to glucocorticoidmediated recruitment of eCB signaling and consequential agonist-induced receptor desensitization (as has been found after sustained elevation of 2-AG signaling; (Schlosburg et al, 2010).

As with most effects of chronic stress (McEwen, 2012b), the loss of eCB signaling in response to homotypic stress is not permanent and recovers passively in a few days (Rossi et al, 2008; Wamsteeker et al, 2010). This recovery, however, can be accelerated if, immediately after homotypic stress, the animal is exposed to a single novel stress (Wamsteeker Cusulin et al, 2014). We propose that stressor salience is the key determinant regulating the efficacy of eCB signaling in the PVN. Specifically, experiences with low salience such as homotypic or repetitive, predictable stress impair presynaptic $\mathrm{CB} 1$ receptor function. By contrast, these changes can be effectively reversed and the eCB system can be re-engaged by a novel stress that has a high relative salience. Importantly, these changes do not occur upstream of the PVN but are directly linked to changes in the local activity of synaptic inputs to PNCs as this effect is recapitulated by enhancing synaptic drive or neuronal activation in the PVN (Wamsteeker Cusulin et al, 2014). This is consistent with findings that ongoing synaptic activity tunes $\mathrm{CB} 1$ receptor function and, as a result, modulates the efficacy of eCB signaling (Chen et al, 2007; Chen et al, 2003). The necessity of synaptic activity for CB1 receptor function is further supported by evidence that the presynaptic activity state has a role in regulation of $\mathrm{eCB}$ inhibition of $\mathrm{GABA}$ release. 
Specifically, increasing presynaptic firing rates in the hippocampus can recover inhibition of GABA release induced by a CB1 receptor agonist, in an N-type $\mathrm{Ca}^{2}$ ${ }^{+}$-channel-dependent manner (Foldy et al, 2006). A similar explanation may underlie observations that exercise can re-set $\mathrm{CB} 1$ receptor sensitivity in the striatum following stress (De Chiara et al, 2010). Future work is required to determine whether the lability of these chronic stress effects on $\mathrm{CB} 1$ receptor function are common throughout the brain or are specific to discrete synapses and circuits.

In addition to synaptic plasticity, there is also evidence that $\mathrm{eCB}$ signaling is important for the regulation of neurogenesis, another form of neuroplasticity. For example, administration of AM404 can reverse acute stress-induced suppression of cell proliferation in the dentate gyrus (Hill et al, 2006). Consistent with this, administration of the phytocannabinoid cannabidiol is capable of reversing chronic stress-induced reductions in neurogenesis and this appears to be driven by a cannabidiol-mediated inhibition of FAAH activity and consequential elevation in AEA levels (Campos et al, 2013). More so, inhibition of MAGL to elevate 2-AG levels during chronic stress similarly prevents impairments in hippocampal neurogenesis (Zhang et al, 2015). As previous work has shown that elevating AEA signaling and promoting $\mathrm{CB} 1$ receptor signaling is capable of promoting cell proliferation and neurogenesis (Aguado et al, 2005; Jiang et al, 2005), these findings imply that impairments in AEA and/or CB1 receptor signaling from chronic stress could result in reductions in neurogenesis.

The functional effects of the loss of eCB-mediated signaling and synaptic plasticity from chronic stress are not completely understood; however, it is increasingly appreciated that impairments in synaptic plasticity render a given neural circuit less flexible and adaptable and may represent a primary substrate underlying the transition of chronic stress into mental illness (Calabrese et al, 2009; McEwen, 2012a; Pittenger and Duman, 2008). Accordingly, chronic stressinduced collapse of eCB signaling may be involved in the development of allostatic load from chronic stress and contribute to the development of psychiatric conditions, such as depression. This hypothesis is consistent with findings that augmenting eCB signaling in the presence of chronic stress can stabilize and curb stress-induced changes in plasticity and produce potential antidepressant- or anxiolytic-like effects (Bortolato et al, 2007; Hill et al, 2013b; Lomazzo et al, 2015; Sumislawski et al, 2011; Zhang et al, 2015; Zhong et al, 2014).

\section{Translational Studies in Humans}

This body of research creates a compelling argument for the importance of $\mathrm{eCB}$ signaling in regulating and mediating multiple aspects of the stress response. Interestingly, experimental studies in human populations are generally consistent with those performed in rodents, and there is significant data indicating the importance of the eCB system to regulate stress and anxiety in humans as well (see Hillard et al, 2012 and Hill and Patel, 2013c for more in-depth reviews). For example, exposure of humans to the Trier social stress test has been found to elevate circulating levels of 2-AG (Hill et al, 2009d) or AEA (Dlugos et al, 2012), indicating that stress exposure in humans similarly elevates an eCB signal. Although it is not clear why AEA was found to elevate, instead of decrease, in response to stress, as is found in the rodent brain studies, however, it is worth noting that both chronic stress and corticosterone treatment are found to increase circulating levels of AEA despite reducing central AEA in rodents (Bowles et al, 2012, 2015; Hill et al, 2008a). Consistent with this, circulating AEA levels have been found to correlate with cortisol in humans (Hill et al, 2013a), suggesting that peripheral glucocorticoids may increase circulating AEA in humans. Interestingly, stress induction, through the use of personally relevant stress-related imagery, has been found to result in a progressive decline in the circulating levels of AEA, suggesting that some stressors may indeed reduce circulating AEA similar to what is seen in the rodent brain (Mangieri et al, 2009).

With respect to functionality, there is a surprisingly consistent body of literature implicating AEA signaling in humans in the regulation of anxiety and amygdala activity. For example, in both healthy and psychiatric populations, lower levels of circulating AEA have been found to correlate with higher anxiety (Dlugos et al, 2012; Hill et al, 2008c). Studies examining the effects of elevated AEA in humans have capitalized on the occurrence of a single-nucleotide polymorphism (SNP) in the FAAH gene that results in elevated levels of AEA (Sipe et al, 2010). Specifically, the substitution of an ancestrally conserved proline to a variant threonine (P129T or C385A) results in reduction in FAAH expression, possibly due to an increased vulnerability to proteolytic degradation (Chiang et al, 2004; Sipe et al, 2002). The recent development of a transgenic mouse possessing this C385A polymorphism in FAAH has verified that a similar reduction in FAAH expression and function, coupled to an increase in AEA levels within the brain, is seen in A carriers (Dincheva et al, 2015). Human carriers of the A allele of this SNP have been found to exhibit reduced activation of the amygdala in response to threat cues, accelerated habituation of the amygdala to threat cues, reduced trait anxiety, increased extinction of fear memories, and enhanced prefrontal-amygdala resting-state coupling (Dincheva et al, 2015; Gunduz-Cinar et al, 2013b; Hariri et al, 2009). Similarly, mouse studies of the A carriers also demonstrate that elevated AEA signaling is associated with reduced anxiety, accelerated fear extinction, increased innervation of prefrontal cortical inputs to the BLA, and reduced activation of the BLA in response to stress (Dincheva et al, 2015). One study has reported increased startle reactivity to emotional cues in A carriers (Conzelmann et al, 2012); however, this process could be functionally distinct from amygdala reactivity and anxiety. Together, these studies demonstrate that AEA signaling is likely an important regulator of anxiety in humans, and this 
effect is likely mediated by dampened activity of the amygdala.

There is also evidence that $\mathrm{eCB}$ signaling in humans is also involved in the HPA axis response to stress. For example, when exposed to parabolic stress, individuals who exhibit an increase in circulating levels of 2-AG exhibit minor changes in HPA axis function, while those who exhibit no change in 2-AG levels possess massive increases in cortisol, indicating an inverse relationship between the ability of an individual to mobilize eCBs in response to stress and the magnitude of HPA axis activation (Chouker et al, 2010). One study has suggested that pharmacological blockade of the CB1 receptor in humans may directly increase cortisol levels, supporting the hypothesis that, similar to rodents, eCB signaling constrains activation of the HPA axis in humans (Goodwin et al, 2012).

The potential importance of the eCB system in regulating emotional behavior in humans was highlighted by the outcomes of the rimonabant trials in humans, where the effects of CB1 receptor blockade were tested in humans for the treatment of obesity. Several studies and meta-analyses demonstrated that indices of anxiety and depression significantly increased following sustained rimonabant treatment (Christensen et al, 2007; Hill and Gorzalka, 2009a; Mitchell and Morris, 2007; Topol et al, 2010); in fact, there was even a published case report of the de novo development of melancholic depression following the onset of rimonabant use (de Mattos Viana et al, 2009). Based on the described role of eCB signaling in the regulation of the neurobehavioral effects of stress, it is reasonable to hypothesize that sustained disruption of eCB signaling could result in the development of anxiety and depression by impairing the buffering effects of eCB signaling on the stress response, rendering the individual more vulnerable to the adverse effects of stress. Consistent with this, experimental studies have demonstrated that administration of rimonabant can directly potentiate stress-induced anxiety (Bergamaschi et al, 2014), promote negative memory bias (Horder et al, 2012), suppress positive memory recall (Horder et al, 2009), and dampen activation of reward circuits in the brain in response to pleasurable stimuli (Horder et al, 2010). Additionally, SNPs in the CB1 receptor gene CNR1 are associated with increased vulnerability to develop depression and anhedonia following early life stress (Agrawal et al, 2012) or current life stress (Juhasz et al, 2009), as well as impaired neural responses to positive emotional stimuli and a heightened likelihood to exhibit antidepressant resistance (Domschke et al, 2008). Although it is not known whether any of these SNPs result in altered CB1 receptor expression or activity, it has been postulated that it could result in decreased mRNA stability and reduced CB1 receptor expression (Domschke et al, 2008). Taken together, these data demonstrate that impairments in $\mathrm{eCB}$ signaling in humans result in an increased sensitivity to the effects of stress, consistent with a stress-buffering role of eCB signaling in humans, and an enhanced vulnerability to develop stressrelated psychiatric illnesses. In line with this, several studies have demonstrated that both depression and posttraumatic stress disorder (PTSD) are associated with reduced levels of circulating eCBs (Hill et al, 2008c, 2009d, 2013a; Neumeister et al, 2013).

\section{CONCLUSIONS AND FUTURE RESEARCH DIRECTIONS}

Collectively, this review provides a broad overview of the rapidly growing field of research investigating the neurobiological interactions between stress and the eCB system. From this analysis, there are several points to emphasize on what the current state of knowledge informs us of this relationship. First, exposure to stress, both acute and chronic, appears to generally result in a bidirectional regulation of the two eCB ligands AEA and 2-AG, with AEA being reduced from stress and 2-AG being increased from stress. The temporal nature of these changes seems to be distinct such that the reduction of AEA appears to occur relatively quickly in response to stress and is mediated by $\mathrm{CRH}$ activating the CRHR1 receptor to increase AEA hydrolysis by FAAH. This mechanism appears to be maintained under conditions of chronic stress where sustained exposure to glucocorticoids upregulates CRH signaling, which maintains long-lasting increases in FAAH and reductions in AEA. In the acute response to stress, this decline in AEA signaling seems to contribute to the manifestation of an anxiety state, the activation of the HPA axis, the impairment in fear extinction, and the suppression of cell proliferation in the neurogenic region of the hippocampus. Under conditions of chronic stress, the more sustained reduction in AEA seems to still contribute not only to all of the facets described above but also may have a role in the development of anhedonia and hyperalgesia. As such, inhibition of FAAH is able to reverse many of the effects of acute and repeated stress.

With respect to acute stress, the increase in 2-AG is delayed and seems to be mediated by increases in corticosterone from stress. The fact that 2-AG responses to stress are amplified under conditions of repeated exposure, which concomitantly results in habituation of corticosterone responses, suggests that a different mechanism contributes to this increase in 2-AG signaling. Ongoing research is seeking to determine what these mechanisms are, but a reduction in MAGL expression at the membrane appears to be one potential factor resulting in enhanced 2-AG signaling capacity after repeated stress (Sumislawski et al, 2011). The primary importance of the increase in 2-AG signaling in response to stress seems to be to buffer and constrain the effects of stress on the brain and facilitate termination of the stress response. Given the effects of CB1 receptor blockade during acute stress, it also seems likely that this increase in 2-AG may contribute to ability of acute stress to promote drug intake (at least alcohol intake), as well as contribute to stress-induced analgesia. At the synaptic level, the ability of glucocorticoids to mobilize 2-AG signaling also seems to be important for many of the shifts in synaptic plasticity that 
take place in response to stress. Under conditions of chronic stress, not only does the progressive increase in 2-AG signaling seem important for stress adaptation and habituation to occur, but the elevated levels of 2-AG may also function to constrain many aspects of stress as blockade of the $\mathrm{CB} 1$ receptor results in an exacerbation of many of the effects of stress, such as anxiety and anhedonia. As such, there seems to be a clear ying-yang relationship for AEA and 2-AG, with both molecules ultimately providing a stressinhibitory role, but the reduction in AEA signaling being relevant for the initiation and manifestation of the effects of stress, while the increase in 2-AG being relevant for tempering and terminating the stress response. These phenomena can be visualized in Figure 3. Moving forward, it will be important to identify the mechanisms by which these changes in eCB signaling occur, the circuit-specificity of these effects, and their impact on synaptic transmission. With the advent of many refined technologies that facilitate the examination of these questions, such as optogenetics or the recently described STORM super-resolution of the CB1 receptor (Dudok et al, 2015), we can hopefully begin to understand the complexity of these phenomena at both a synaptic level and a circuit level.

Another concept that merits further attention here is the potential relevance of the collapse of CB1 receptor signaling following chronic stress. Throughout this review, we have highlighted these data indicating the importance of eCB signaling in buffering against the effects of stress, thus it is not surprising that the impairments in this system that emerge following chronic stress seem to associate with the development of adverse responses, such as anxiety and anhedonia, which are classically linked with the onset of psychiatric conditions. In the past few decades, the concept of allostatic load has been championed by Bruce McEwen (Karatsoreos and McEwen, 2011), whereby it is hypothesized that the continual wear and tear from stress exposure results in an increased vulnerability to the adverse effects of stress. In this context, it is interesting to consider the possibility that a collapse of the $\mathrm{eCB}$ system could be a contributor to the effects of allostatic load. This is consistent with the fact that impairments in this system are associated with a greater vulnerability to stress-induced mental illnesses and that, in the animal models, augmentation of the eCB system can ward off the development of many of these adverse effects of chronic stress that are signs of allostatic load. Future work, both basic and clinical, should further investigate whether impairments in the $\mathrm{eCB}$ system are a potential contributor to allostatic load and, more so, if there are biomarkers in this system that could act as an index of stress fatigue or a predictive measure for vulnerability to psychiatric illness.

Based on these data, there has been a significant interest in therapeutics development around $\mathrm{eCB}$ augmenting agents for stress-related neuropsychiatric disorders (see (Gaetani et al, 2009; Hill et al, 2009b; Hill and Patel, 2013c; Neumeister et al, 2015). Results of pending clinical trials with FAAH inhibitors will reveal therapeutic potential of this
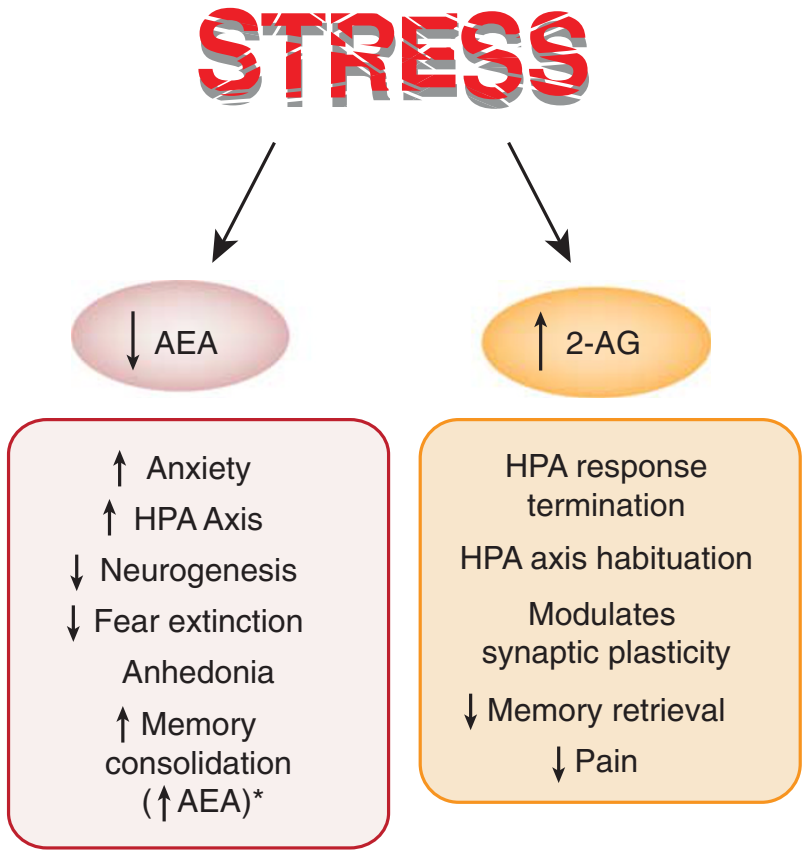

Figure 3. Schematic illustration of behavioral outputs regulated by the interaction between stress and endocannabinoids. Exposure to stress, both acute and chronic, generally results in a bidirectional regulation of anandamide (AEA) and 2-arachidonoyl glycerol (2-AG), with AEA being reduced and 2-AG being increased from stress. Although the behavioral outputs regulated by AEA and 2-AG in some cases likely overlap, the decline in AEA signaling seems to mainly contribute not only to the manifestation of an anxiety state, the activation of the HPA axis, the suppression of neurogenesis in the hippocampus, and an impairment in fear extinction but also may have a role in the development of anhedonia and hyperalgesia. Unlike AEA, the behavioral influences of 2-AG are less characterized as selective tools for manipulating 2-AG signaling have only been recently developed. The stress-induced increase in 2-AG is believed to buffer and constrain the effects of stress on the brain, particularly by contributing to termination of stress-induced HPA axis activation and promoting habituation to stress, to possibly contribute to the ability of acute stress to shift synaptic plasticity, to mediate stress impairing effects on memory retrieval, and contribute to stress-induced analgesia. *Interestingly, with respect to memory consolidation, it appears that the stress/pain associated with the training procedure (ie, footshock exposure) leads to an increase in limbic AEA levels that, in turn, contributes to enhance aversive memory consolidation, distinguishing this effect from the other noted effects that are related to the decline in AEA signaling typically seen following stress.

class of drug for stress-related psychiatric disorder, particularly PTSD and possibly major depression. The potential utility of MAGL inhibitors could be more problematic, as unlike the fact that chronic elevations in AEA do not seem to modulate CB1 receptor function (Lichtman et al, 2002), chronic elevations in 2-AG signaling, through administration of high doses of MAGL inhibitors, seem to clearly desensitize the CB1 receptor (Schlosburg et al, 2010). As such, the utility of these drugs may be more limited, although additional studies have indicated that lower-dose titrations of MAGL inhibitors do not result in a desensitization of CB1 receptors (Kinsey et al, 2013). That being said, the possibility of alternate routes of interfering with $\mathrm{eCB}$ metabolism seems 
like a possibility as well. For example, recent studies have identified an additional eCB inactivation pathway mediated by COX-2, which may regulate anxiety-related behaviors and stress responses (Hermanson et al, 2013). The recent development of substrate-selective inhibitors of COX-2 have allowed for the pharmacological dissection of COX-2regulated $\mathrm{eCB}$ signaling and prostaglandin production. Substrate-selective COX-2 inhibitors increase brain eCB levels without decreasing prostaglandin levels and cause CB1-dependent anxiolytic actions (Hermanson et al, 2014). Whether COX-2-regulated eCBs regulate behavioral stress responses is not yet known, however, COX-2 is an immediate early gene whose expression is upregulated by stress, suggesting that this pathway could be highly relevant during stress exposure. Similar to this approach, a noncanonical pathway of eCB metabolism has recently been identified to potentially be important for the regulation of eCB signaling under conditions of chronic stress. Here the protein-tyrosine phosphatase 1B (PTP1B) was found to regulate $\mathrm{eCB}$ production through an mGluR5-dependent pathway, which was increased following chronic stress, and inhibition of PTP1B was found to partially rescue the stressinduced reductions in amygdalar $\mathrm{eCB}$ levels and reverse stress-induced anxiety (Qin et al, 2015). As such, the possibility of therapeutic interventions of the eCB system in the context of stress-related psychiatric conditions opens many doors to novel therapeutics.

In summary, the eCB system is clearly an important signaling system integrated into the neural regulation of the stress response. This is consistent with the fact that humans have been consuming cannabis for centuries, largely because of its stress-reducing qualities (Green et al, 2003). As it is becoming increasingly appreciated that $\mathrm{eCB}$ signaling likely represents a mediator of homeostasis, both at the synaptic level and at the systems level of emotional regulation, it will be important moving forward to understand whether perturbations in this system could be important for a wide array of stimuli and disturbances that can lead to changes in stress sensitivity and anxiety, such as obesity and other chronic diseases. A combined approach of pharmacology, genetics, and advanced neuroscientific techniques will hopefully pave the way for our growing understanding of the importance of eCB signaling to keep the brain calm and help us deal with the rapidly growing burden of stress in our society.

\section{FUNDING AND DISCLOSURE}

$\mathrm{MNH}$ and JSB receive operating funds from the Canadian Institutes of Health Research and MNH holds a Tier II Canada Research Chair and SP from the National Institutes of Health (MH090412 and R21 MH103515). MM receives salary support from an Eyes High Fellowship from the University of Calgary. MNH consults with Pfizer; all the other authors declare no financial conflicts. The funding sources had no influence on the writing of this manuscript.

\section{REFERENCES}

Agrawal A, Nelson EC, Littlefield AK, Bucholz KK, Degenhardt L, Henders AK et al (2012). Cannabinoid receptor genotype moderation of the effects of childhood physical abuse on anhedonia and depression. Arch Gen Psychiatry 69: 732-740.

Aguado T, Monory K, Palazuelos J, Stella N, Cravatt B, Lutz B et al (2005). The endocannabinoid system drives neural progenitor proliferation. FASEB $J 19$ 1704-1706.

Ahn K, McKinney MK, Cravatt BF (2008). Enzymatic pathways that regulate endocannabinoid signaling in the nervous system. Chem Rev 108: 1687-1707.

Akirav I, Kozenicky M, Tal D, Sandi C, Venero C, Richter-Levin G (2004). A facilitative role for corticosterone in the acquisition of a spatial task under moderate stress. Learn Mem 11: 188-195.

Aliczki M, Balogh Z, Tulogdi A, Haller J (2012). The temporal dynamics of the effects of monoacylglycerol lipase blockade on locomotion, anxiety, and body temperature. Behav Pharmacol 23: 348-357.

Aliczki M, Zelena D, Mikics E, Varga ZK, Pinter O, Bakos NV et al (2013). Monoacylglycerol lipase inhibition-induced changes in plasma corticosterone levels, anxiety and locomotor activity in male CD1 mice. Horm Behav 63: 752-758.

Atkinson HC, Leggett JD, Wood SA, Castrique ES, Kershaw YM, Lightman SL (2010). Regulation of the hypothalamic-pituitary-adrenal axis circadian rhythm by endocannabinoids is sexually diergic. Endocrinology 151: 3720-3727.

Atsak P, Hauer D, Campolongo P, Schelling G, Fornari RV, Roozendaal B (2014). Endocannabinoid signaling within the basolateral amygdala integrates multiple stress hormone effects on memory consolidation. Neuropsychopharmacology 40: $1485-1494$.

Atsak P, Hauer D, Campolongo P, Schelling G, McGaugh JL, Roozendaal B (2012a). Glucocorticoids interact with the hippocampal endocannabinoid system in impairing retrieval of contextual fear memory. Proc Natl Acad Sci USA 109 3504-3509.

Atsak P, Roozendaal B, Campolongo P (2012b). Role of the endocannabinoid system in regulating glucocorticoid effects on memory for emotional experiences. Neuroscience 204: 104-116.

Atwood BK, Mackie K (2010). CB2: a cannabinoid receptor with an identity crisis. Br J Pharmacol 160: 467-479.

Atwood BK, Straiker A, Mackie K (2012). CB(2): therapeutic target-in-waiting Prog Neuropsychopharmacol Biol Psychiatry 38: 16-20.

Azad SC, Eder M, Marsicano G, Lutz B, Zieglgansberger W, Rammes G (2003) Activation of the cannabinoid receptor type 1 decreases glutamatergic and GABAergic synaptic transmission in the lateral amygdala of the mouse. Learn Mem 10: 116-128.

Azad SC, Kurz J, Marsicano G, Lutz B, Zieglgansberger W, Rammes G (2008). Activation of CB1 specifically located on GABAergic interneurons inhibits LTD in the lateral amygdala. Learn Mem 15: 143-152.

Bains JS, Cusulin JI, Inoue W (2015). Stress-related synaptic plasticity in the hypothalamus. Nat Rev Neurosci 16: 377-388.

Bedse G, Colangeli R, Lavecchia AM, Romano A, Altieri F, Cifani C et al (2014). Role of the basolateral amygdala in mediating the effects of the fatty acid amide hydrolase inhibitor URB597 on HPA axis response to stress. Eur Neuropsychopharmacol 24: 1511-1523.

Bellocchio L, Soria-Gomez E, Quarta C, Metna-Laurent M, Cardinal P, Binder E et al (2013). Activation of the sympathetic nervous system mediates hypophagic and anxiety-like effects of $\mathrm{CB}(1)$ receptor blockade. Proc Natl Acad Sci USA 110: 4786-4791.

Bentz D, Michael T, Wilhelm FH, Hartmann FR, Kunz S, von Rohr IR et al (2013). Influence of stress on fear memory processes in an aversive differential conditioning paradigm in humans. Psychoneuroendocrinology 38: 1186-1197.

Bergamaschi MM, Queiroz RH, Chagas MH, Linares IM, Arrais KC, de Oliveira DC et al (2014). Rimonabant effects on anxiety induced by simulated public speaking in healthy humans: a preliminary report. Hum Psychopharmacol 29 94-99.

Bishop SJ (2008). Neural mechanisms underlying selective attention to threat Ann NY Acad Sci 1129: 141-152.

Bisogno T, Howell F, Williams G, Minassi A, Cascio MG, Ligresti A et al (2003). Cloning of the first sn1-DAG lipases points to the spatial and temporal regulation of endocannabinoid signaling in the brain. J Cell Biol 163: 463-468.

Bitencourt RM, Pamplona FA, Takahashi RN (2008). Facilitation of contextual fear memory extinction and anti-anxiogenic effects of AM404 and cannabidiol in conditioned rats. Eur Neuropsychopharmacol 18: 849-859.

Bitencourt RM, Pamplona FA, Takahashi RN (2014). Corticosteroidendocannabinoid loop supports decrease of fear-conditioned response in rats. Eur Neuropsychopharmacol 24: 1091-1102.

Blankman JL, Simon GM, Cravatt BF (2007). A comprehensive profile of brain enzymes that hydrolyze the endocannabinoid 2-arachidonoylglycerol. Chem Biol 14: $1347-1356$ 
Bluett RJ, Gamble-George JC, Hermanson DJ, Hartley ND, Marnett LJ, Patel S (2014). Central anandamide deficiency predicts stress-induced anxiety: behavioral reversal through endocannabinoid augmentation. Trans/ Psychiatry 4: e408.

Bortolato M, Mangieri RA, Fu J, Kim JH, Arguello O, Duranti A et al (2007). Antidepressant-like activity of the fatty acid amide hydrolase inhibitor URB597 in a rat model of chronic mild stress. Biol Psychiatry 62: 1103-1110.

Bouchez G, Millan MJ, Rivet JM, Billiras R, Boulanger R, Gobert A (2012). Quantification of extracellular levels of corticosterone in the basolateral amygdaloid complex of freely-moving rats: a dialysis study of circadian variation and stress-induced modulation. Brain Res 1452: 47-60.

Bowles NP, Hill MN, Bhagat SM, Karatsoreos IN, Hillard CJ, McEwen BS (2012). Chronic, noninvasive glucocorticoid administration suppresses limbic endocannabinoid signaling in mice. Neuroscience 204: 83-89.

Bowles NP, Karatsoreos IN, Li X, Vemuri VK, Wood JA, Li Z et al (2015). A peripheral endocannabinoid mechanism contributes to glucocorticoid-mediated metabolic syndrome. Proc Natl Acad Sci USA 112: 285-290.

Bucherelli C, Baldi E, Mariottini C, Passani MB, Blandina P (2006). Aversive memory reactivation engages in the amygdala only some neurotransmitters involved in consolidation. Learn Mem 13: 426-430.

Busquets-Garcia A, Puighermanal E, Pastor A, de la Torre R, Maldonado R, Ozaita A (2011). Differential role of anandamide and 2-arachidonoylglycerol in memory and anxiety-like responses. Biol Psychiatry 70: 479-486.

Calabrese F, Molteni R, Racagni G, Riva MA (2009). Neuronal plasticity: a link between stress and mood disorders. Psychoneuroendocrinology 34(Suppl 1): S208-S216.

Campolongo P, Ratano P, Manduca A, Scattoni ML, Palmery M, Trezza V et al (2012). The endocannabinoid transport inhibitor AM404 differentially modulates recognition memory in rats depending on environmental aversiveness. Front Behav Neurosci 6: 11 .

Campolongo P, Roozendaal B, Trezza V, Hauer D, Schelling G, McGaugh JL et al (2009). Endocannabinoids in the rat basolateral amygdala enhance memory consolidation and enable glucocorticoid modulation of memory. Proc Natl Acad Sci USA 106: 4888-4893.

Campos AC, Ferreira FR, Guimaraes FS, Lemos Jl (2010). Facilitation of endocannabinoid effects in the ventral hippocampus modulates anxiety-like behaviors depending on previous stress experience. Neuroscience 167: 238-246.

Campos AC, Ortega Z, Palazuelos J, Fogaca MV, Aguiar DC, Diaz-Alonso J et al (2013). The anxiolytic effect of cannabidiol on chronically stressed mice depends on hippocampal neurogenesis: involvement of the endocannabinoid system. Int J Neuropsychopharmacol 16: 1407-1419.

Chen K, Neu A, Howard AL, Foldy C, Echegoyen J, Hilgenberg L et al (2007). Prevention of plasticity of endocannabinoid signaling inhibits persistent limbic hyperexcitability caused by developmental seizures. J Neurosci 27: 46-58.

Chen K, Ratzliff A, Hilgenberg L, Gulyas A, Freund TF, Smith M et al (2003). Longterm plasticity of endocannabinoid signaling induced by developmental febrile seizures. Neuron 39: 599-611.

Chhatwal JP, Davis M, Maguschak KA, Ressler KJ (2005). Enhancing cannabinoid neurotransmission augments the extinction of conditioned fear. Neuropsychopharmacology 30: 516-524.

Chiang KP, Gerber AL, Sipe JC, Cravatt BF (2004). Reduced cellular expression and activity of the P129T mutant of human fatty acid amide hydrolase: evidence for a link between defects in the endocannabinoid system and problem drug use. Hum Mol Genet 13: 2113-2119.

Chouker A, Kaufmann I, Kreth S, Hauer D, Feuerecker M, Thieme D et al (2010). Motion sickness, stress and the endocannabinoid system. PLoS One 5: e10752.

Christensen R, Kristensen PK, Bartels EM, Bliddal H, Astrup A (2007). Efficacy and safety of the weight-loss drug rimonabant: a meta-analysis of randomised trials. Lancet 370: 1706-1713.

Conzelmann A, Reif A, Jacob C, Weyers P, Lesch KP, Lutz B et al (2012). A polymorphism in the gene of the endocannabinoid-degrading enzyme FAAH (FAAH C385A) is associated with emotional-motivational reactivity. Psychopharmacology (Berl) 224: 573-579.

Cravatt BF, Demarest K, Patricelli MP, Bracey MH, Giang DK, Martin BR et al (2001). Supersensitivity to anandamide and enhanced endogenous cannabinoid signaling in mice lacking fatty acid amide hydrolase. Proc Natl Acad Sci USA 98: 9371-9376.

Cristino L, Starowicz K, De Petrocellis L, Morishita J, Ueda N, Guglielmotti V et al (2008). Immunohistochemical localization of anabolic and catabolic enzymes for anandamide and other putative endovanilloids in the hippocampus and cerebellar cortex of the mouse brain. Neuroscience 151: 955-968.

Dallman MF (2005). Adrenocortical function, feedback, and alphabet soup. Am J Physiol Endocrinol Metab 289: E361-E362.

De Chiara V, Errico F, Musella A, Rossi S, Mataluni G, Sacchetti L et al (2010). Voluntary exercise and sucrose consumption enhance cannabinoid CB1 receptor sensitivity in the striatum. Neuropsychopharmacology 35: 374-387. de Kloet ER, Oitzl MS, Joels M (1999). Stress and cognition: are corticosteroids good or bad guys? Trends Neurosci 22: 422-426.

de Mattos Viana B, Prais HA, Daker MV (2009). Melancholic features related to rimonabant. Gen Hosp Psychiatry 31: 583-585.

de Oliveira Alvares L, de Oliveira LF, Camboim C, Diehl F, Genro BP, Lanziotti VB et al (2005). Amnestic effect of intrahippocampal AM251, a CB1-selective blocker, in the inhibitory avoidance, but not in the open field habituation task, in rats. Neurobiol Learn Mem 83: 119-124.

de Oliveira Alvares L, Engelke DS, Diehl F, Scheffer-Teixeira R, Haubrich J, de Freitas Cassini L et al (2010). Stress response recruits the hippocampal endocannabinoid system for the modulation of fear memory. Learn Mem 17: 202-209.

de Oliveira Alvares L, Genro BP, Vaz Breda R, Pedroso MF, Da Costa JC, Quillfeldt JA (2006). AM251, a selective antagonist of the CB1 receptor, inhibits the induction of long-term potentiation and induces retrograde amnesia in rats. Brain Res 1075: 60-67.

de Quervain DJ, Aerni A, Schelling G, Roozendaal B (2009). Glucocorticoids and the regulation of memory in health and disease. Front Neuroendocrinol 30: 358-370.

de Quervain DJ, Roozendaal B, McGaugh JL (1998). Stress and glucocorticoids impair retrieval of long-term spatial memory. Nature 394: 787-790.

De Vries TJ, Shaham Y, Homberg JR, Crombag H, Schuurman K, Dieben J et al (2001). A cannabinoid mechanism in relapse to cocaine seeking. Nat Med 7: 1151-1154.

DePoy L, Daut R, Brigman JL, MacPherson K, Crowley N, Gunduz-Cinar O et al (2013). Chronic alcohol produces neuroadaptations to prime dorsal striatal learning. Proc Natl Acad Sci USA 110: 14783-14788.

Devane WA, Hanus L, Breuer A, Pertwee RG, Stevenson LA, Griffin G et al (1992). Isolation and structure of a brain constituent that binds to the cannabinoid receptor. Science 258: 1946-1949.

Di Marzo V, De Petrocellis L (2012). Why do cannabinoid receptors have more than one endogenous ligand?. Philos Trans R Soc Lond B Biol Sci 367: 3216-3228.

Di S, Malcher-Lopes R, Halmos KC, Tasker JG (2003). Nongenomic glucocorticoid inhibition via endocannabinoid release in the hypothalamus: a fast feedback mechanism. J Neurosci 23: 4850-4857.

Di S, Malcher-Lopes R, Marcheselli VL, Bazan NG, Tasker JG (2005). Rapid glucocorticoid-mediated endocannabinoid release and opposing regulation of glutamate and gamma-aminobutyric acid inputs to hypothalamic magnocellular neurons. Endocrinology 146: 4292-4301.

Dincheva I, Drysdale AT, Hartley CA, Johnson DC, Jing D, King EC et al (2015). FAAH genetic variation enhances fronto-amygdala function in mouse and human. Nat Commun 6: 6395.

Dinh TP, Carpenter D, Leslie FM, Freund TF, Katona I, Sensi SL et al (2002). Brain monoglyceride lipase participating in endocannabinoid inactivation. Proc Natl Acad Sci USA 99: 10819-10824.

Diorio D, Viau V, Meaney MJ (1993). The role of the medial prefrontal cortex (cingulate gyrus) in the regulation of hypothalamic-pituitary-adrenal responses to stress. J Neurosci 13: 3839-3847.

Dlugos A, Childs E, Stuhr KL, Hillard CJ, de Wit H (2012). Acute stress increases circulating anandamide and other $\mathrm{N}$-acylethanolamines in healthy humans. Neuropsychopharmacology 37: 2416-2427.

Dominguez G, Faucher P, Henkous N, Krazem A, Pierard C, Beracochea D (2014). Stress induced a shift from dorsal hippocampus to prefrontal cortex dependent memory retrieval: role of regional corticosterone. Front Behav Neurosci 8: 166.

Domschke K, Dannlowski U, Ohrmann P, Lawford B, Bauer J, Kugel H et al (2008). Cannabinoid receptor 1 (CNR1) gene: impact on antidepressant treatment response and emotion processing in major depression. Eur Neuropsychopharmacol 18: 751-759.

Doyon C, Denis RG, Baraboi ED, Samson P, Lalonde J, Deshaies Y et al (2006). Effects of rimonabant (SR141716) on fasting-induced hypothalamic-pituitaryadrenal axis and neuronal activation in lean and obese Zucker rats. Diabetes 55: 3403-3410.

Dubreucq S, Matias I, Cardinal P, Haring M, Lutz B, Marsicano G et al (2012). Genetic dissection of the role of cannabinoid type-1 receptors in the emotional consequences of repeated social stress in mice. Neuropsychopharmacology 37: 1885-1900.

Dudok B, Barna L, Ledri M, Szabo SI, Szabadits E, Pinter B et al (2015). Cell-specific STORM super-resolution imaging reveals nanoscale organization of cannabinoid signaling. Nat Neurosci 18: 75-86.

Economidou D, Mattioli L, Cifani C, Perfumi M, Massi M, Cuomo V et al (2006). Effect of the cannabinoid CB1 receptor antagonist SR-141716A on ethanol selfadministration and ethanol-seeking behaviour in rats. Psychopharmacology (Berl) 183: 394-403

Evanson NK, Tasker JG, Hill MN, Hillard CJ, Herman JP (2010). Fast feedback inhibition of the HPA axis by glucocorticoids is mediated by endocannabinoid signaling. Endocrinology 151: 4811-4819. 
Fokos S, Panagis G (2010). Effects of delta9-tetrahydrocannabinol on reward and anxiety in rats exposed to chronic unpredictable stress. J Psychopharmacol 24: $767-777$.

Foldy C, Neu A, Jones MV, Soltesz I (2006). Presynaptic, activity-dependent modulation of cannabinoid type 1 receptor-mediated inhibition of GABA release. J Neurosci 26: 1465-1469.

Friemel CM, Zimmer A, Schneider M (2014). The CB1 receptor as an important mediator of hedonic reward processing. Neuropsychopharmacology 39: 2387-2396.

Fu J, Bottegoni G, Sasso O, Bertorelli R, Rocchia W, Masetti M et al (2011). A catalytically silent FAAH-1 variant drives anandamide transport in neurons. Nat Neurosci 15: 64-69.

Gaetani S, Dipasquale P, Romano A, Righetti L, Cassano T, Piomelli D et al (2009). The endocannabinoid system as a target for novel anxiolytic and antidepressant drugs. Int Rev Neurobiol 85: 57-72.

Gamble-George JC, Conger JR, Hartley ND, Gupta P, Sumislawski JJ, Patel S (2013). Dissociable effects of CB1 receptor blockade on anxiety-like and consummatory behaviors in the novelty-induced hypophagia test in mice. Psychopharmacology (Berl) 228: 401-409.

Ganon-Elazar E, Akirav I (2009). Cannabinoid receptor activation in the basolateral amygdala blocks the effects of stress on the conditioning and extinction of inhibitory avoidance. J Neurosci 29: 11078-11088.

Ginsberg AB, Pecoraro NC, Warne JP, Horneman HF, Dallman MF (2010). Rapid alteration of stress-induced hypothalamic-pituitary-adrenal hormone secretion in the rat: a comparison of glucocorticoids and cannabinoids. Stress 13: 248-257.

Glangetas C, Girard D, Groc L, Marsicano G, Chaouloff F, Georges F (2013). Stress switches cannabinoid type-1 (CB1) receptor-dependent plasticity from LTD to LTP in the bed nucleus of the stria terminalis. J Neurosci 33: 19657-19663.

Goodwin RS, Baumann MH, Gorelick DA, Schwilke E, Schwope DM, Darwin WD et al (2012). CB1-cannabinoid receptor antagonist effects on cortisol in cannabis-dependent men. Am J Drug Alcohol Abuse 38: 114-119.

Gorzalka BB, Hill MN, Hillard CJ (2008). Regulation of endocannabinoid signaling by stress: implications for stress-related affective disorders. Neurosci Biobehav Rev 32: 1152-1160.

Gray JM, Vecchiarelli HA, Morena M, Lee T, Hermanson DJ, Kim AB et al (2015). Corticotropin-releasing hormone drives anandamide hydrolysis in the amygdala to promote anxiety. J Neurosci 35: 3879-3892.

Gray M, Bingham B, Viau V (2010). A comparison of two repeated restraint stress paradigms on hypothalamic-pituitary-adrenal axis habituation, gonadal status and central neuropeptide expression in adult male rats. J Neuroendocrinol 22: 92-101.

Green B, Kavanagh D, Young R (2003). Being stoned: a review of self-reported cannabis effects. Drug Alcohol Rev 22: 453-460.

Grissom N, Bhatnagar S (2009). Habituation to repeated stress: get used to it. Neurobiol Learn Mem 92: 215-224.

Gulyas Al, Cravatt BF, Bracey MH, Dinh TP, Piomelli D, Boscia F et al (2004). Segregation of two endocannabinoid-hydrolyzing enzymes into pre- and postsynaptic compartments in the rat hippocampus, cerebellum and amygdala. Eur J Neurosci 20: 441-458.

Gunduz-Cinar O, Hill MN, McEwen BS, Holmes A (2013a). Amygdala FAAH and anandamide: mediating protection and recovery from stress. Trends Pharmacol Sci 34: 637-644.

Gunduz-Cinar O, MacPherson KP, Cinar R, Gamble-George J, Sugden K, Williams B et al (2013b). Convergent translational evidence of a role for anandamide in amygdala-mediated fear extinction, threat processing and stress-reactivity. $\mathrm{Mol}$ Psychiatry 18: 813-823.

Haj-Dahmane S, Shen RY (2014). Chronic stress impairs alpha1-adrenoceptorinduced endocannabinoid-dependent synaptic plasticity in the dorsal raphe nucleus. J Neurosci 34: 14560-14570.

Haller J, Bakos N, Szirmay M, Ledent C, Freund TF (2002). The effects of genetic and pharmacological blockade of the CB1 cannabinoid receptor on anxiety. Eur J Neurosci 16: 1395-1398.

Haller J, Barna I, Barsvari B, Gyimesi Pelczer K, Yasar S, Panlilio LV et al (2009). Interactions between environmental aversiveness and the anxiolytic effects of enhanced cannabinoid signaling by FAAH inhibition in rats. Psychopharmacology (Berl) 204: 607-616.

Haller J, Goldberg SR, Pelczer KG, Aliczki M, Panlilio LV (2013). The effects of anandamide signaling enhanced by the FAAH inhibitor URB597 on coping styles in rats. Psychopharmacology (Berl) 230: 353-362.

Haller J, Varga B, Ledent C, Freund TF (2004). CB1 cannabinoid receptors mediate anxiolytic effects: convergent genetic and pharmacological evidence with CB1specific agents. Behav Pharmacol 15: 299-304.

Haring M, Marsicano G, Lutz B, Monory K (2007). Identification of the cannabinoid receptor type 1 in serotonergic cells of raphe nuclei in mice. Neuroscience 146: 1212-1219.
Hariri AR, Gorka A, Hyde LW, Kimak M, Halder I, Ducci F et al (2009). Divergent effects of genetic variation in endocannabinoid signaling on human threat- and reward-related brain function. Biol Psychiatry 66: 9-16.

Heinzmann JM, Thoeringer CK, Knapman A, Palme R, Holsboer F, Uhr M et al (2010). Intrahippocampal corticosterone response in mice selectively bred for extremes in stress reactivity: a microdialysis study. J Neuroendocrinol 22: 1187-1197.

Herkenham M, Lynn AB, Johnson MR, Melvin LS, de Costa BR, Rice KC (1991). Characterization and localization of cannabinoid receptors in rat brain: a quantitative in vitro autoradiographic study. J Neurosci 11: 563-583.

Herkenham M, Lynn AB, Little MD, Johnson MR, Melvin LS, de Costa BR et al (1990). Cannabinoid receptor localization in brain. Proc Natl Acad Sci USA 87: 1932-1936.

Hermann H, Marsicano G, Lutz B (2002). Coexpression of the cannabinoid receptor type 1 with dopamine and serotonin receptors in distinct neuronal subpopulations of the adult mouse forebrain. Neuroscience 109: 451-460.

Hermans EJ, Battaglia FP, Atsak P, de Voogd LD, Fernandez G, Roozendaal B (2014a). How the amygdala affects emotional memory by altering brain network properties. Neurobiol Learn Mem 112: 2-16.

Hermans EJ, Henckens MJ, Joels M, Fernandez G (2014b). Dynamic adaptation of large-scale brain networks in response to acute stressors. Trends Neurosci 37: 304-314.

Hermanson DJ, Gamble-George JC, Marnett LJ, Patel S (2014). Substrate-selective COX-2 inhibition as a novel strategy for therapeutic endocannabinoid augmentation. Trends Pharmacol Sci 35: 358-367.

Hermanson DJ, Hartley ND, Gamble-George J, Brown N, Shonesy BC, Kingsley PJ et al (2013). Substrate-selective COX-2 inhibition decreases anxiety via endocannabinoid activation. Nat Neurosci 16: 1291-1298.

Hill MN, Bierer LM, Makotkine I, Golier JA, Galea S, McEwen BS et al (2013a). Reductions in circulating endocannabinoid levels in individuals with post-traumatic stress disorder following exposure to the World Trade Center attacks. Psychoneuroendocrinology 38: 2952-2961.

Hill MN, Carrier EJ, Ho WS, Shi L, Patel S, Gorzalka BB et al (2008a). Prolonged glucocorticoid treatment decreases cannabinoid CB1 receptor density in the hippocampus. Hippocampus 18: 221-226.

Hill MN, Carrier EJ, McLaughlin RJ, Morrish AC, Meier SE, Hillard CJ et al (2008b). Regional alterations in the endocannabinoid system in an animal model of depression: effects of concurrent antidepressant treatment. J Neurochem 106: 2322-2336.

Hill MN, Gorzalka BB (2004). Enhancement of anxiety-like responsiveness to the cannabinoid $\mathrm{CB}(1)$ receptor agonist $\mathrm{HU}-210$ following chronic stress. Eur J Pharmacol 499: 291-295.

Hill MN, Gorzalka BB (2009a). The endocannabinoid system and the treatment of mood and anxiety disorders. CNS Neurol Disord Drug Targets 8: 451-458.

Hill MN, Hillard CJ, Bambico FR, Patel S, Gorzalka BB, Gobbi G (2009b). The therapeutic potential of the endocannabinoid system for the development of a novel class of antidepressants. Trends Pharmacol Sci 30: 484-493.

Hill MN, Hillard CJ, McEwen BS (2011a). Alterations in corticolimbic dendritic morphology and emotional behavior in cannabinoid CB1 receptor-deficient mice parallel the effects of chronic stress. Cereb Cortex 21: 2056-2064.

Hill MN, Ho WS, Meier SE, Gorzalka BB, Hillard CJ (2005a). Chronic corticosterone treatment increases the endocannabinoid 2-arachidonylglycerol in the rat amygdala. Eur J Pharmacol 528: 99-102.

Hill MN, Kambo JS, Sun JC, Gorzalka BB, Galea LA (2006). Endocannabinoids modulate stress-induced suppression of hippocampal cell proliferation and activation of defensive behaviours. Eur J Neurosci 24: 1845-1849.

Hill MN, Karatsoreos IN, Hillard CJ, McEwen BS (2010a). Rapid elevations in limbic endocannabinoid content by glucocorticoid hormones in vivo. Psychoneuroendocrinology 35: 1333-1338.

Hill MN, Kumar SA, Filipski SB, Iverson M, Stuhr KL, Keith JM et al (2013b). Disruption of fatty acid amide hydrolase activity prevents the effects of chronic stress on anxiety and amygdalar microstructure. Mol Psychiatry 18: 1125-1135.

Hill MN, McLaughlin RJ, Bingham B, Shrestha L, Lee T, Gray JM et al (2010b). Endogenous cannabinoid signaling is essential for stress adaptation. Proc Natl Acad Sci USA 107: 9406-9411.

Hill MN, McLaughlin RJ, Morrish AC, Viau V, Floresco SB, Hillard CJ et al (2009c). Suppression of amygdalar endocannabinoid signaling by stress contributes to activation of the hypothalamic-pituitary-adrenal axis. Neuropsychopharmacology 34: 2733-2745.

Hill MN, McLaughlin RJ, Pan B, Fitzgerald ML, Roberts CJ, Lee TT et al (2011b). Recruitment of prefrontal cortical endocannabinoid signaling by glucocorticoids contributes to termination of the stress response. J Neurosci 31: 10506-10515. Hill MN, Miller GE, Carrier EJ, Gorzalka BB, Hillard CJ (2009d). Circulating endocannabinoids and $\mathrm{N}$-acyl ethanolamines are differentially regulated in major 
depression and following exposure to social stress. Psychoneuroendocrinology 34: 1257-1262.

Hill MN, Miller GE, Ho WS, Gorzalka BB, Hillard CJ (2008c). Serum endocannabinoid content is altered in females with depressive disorders: a preliminary report. Pharmacopsychiatry 41: 48-53.

Hill MN, Patel S (2013c). Translational evidence for the involvement of the endocannabinoid system in stress-related psychiatric illnesses. Biol Mood Anxiety Disord 3: 19.

Hill MN, Patel S, Carrier EJ, Rademacher DJ, Ormerod BK, Hillard CJ et al (2005b). Downregulation of endocannabinoid signaling in the hippocampus following chronic unpredictable stress. Neuropsychopharmacology 30: 508-515.

Hill MN, Tasker JG (2012). Endocannabinoid signaling, glucocorticoid-mediated negative feedback, and regulation of the hypothalamic-pituitary-adrenal axis. Neuroscience 204: 5-16.

Hillard CJ, Edgemond WS, Jarrahian A, Campbell WB (1997). Accumulation of $\mathrm{N}$-arachidonoylethanolamine (anandamide) into cerebellar granule cells occurs via facilitated diffusion. J Neurochem 69: 631-638.

Hillard CJ, Weinlander KM, Stuhr KL (2012). Contributions of endocannabinoid signaling to psychiatric disorders in humans: genetic and biochemical evidence. Neuroscience 204: 207-229.

Hohmann AG, Suplita RL, Bolton NM, Neely MH, Fegley D, Mangieri R et al (2005). An endocannabinoid mechanism for stress-induced analgesia. Nature 435: 1108-1112.

Hong S, Zheng G, Wu X, Snider NT, Owyang C, Wiley JW (2011). Corticosterone mediates reciprocal changes in CB 1 and TRPV1 receptors in primary sensory neurons in the chronically stressed rat. Gastroenterology 140: 627-637 e624.

Horder J, Browning M, Di Simplicio M, Cowen PJ, Harmer CJ (2012). Effects of 7 days of treatment with the cannabinoid type 1 receptor antagonist, rimonabant, on emotional processing. J Psychopharmacol 26: 125-132.

Horder J, Cowen PJ, Di Simplicio M, Browning M, Harmer CJ (2009). Acute administration of the cannabinoid CB1 antagonist rimonabant impairs positive affective memory in healthy volunteers. Psychopharmacology (Berl) 205: 85-91.

Horder J, Harmer CJ, Cowen PJ, McCabe C (2010). Reduced neural response to reward following 7 days treatment with the cannabinoid CB1 antagonist rimonabant in healthy volunteers. Int J Neuropsychopharmacol 13: 1103-1113.

Howlett AC, Barth F, Bonner TI, Cabral G, Casellas P, Devane WA et al (2002). International Union of Pharmacology. XXVII. Classification of cannabinoid receptors. Pharmacol Rev 54: 161-202.

Hu SS, Ho YC, Chiou LC (2014). No more pain upon Gq-protein-coupled receptor activation: role of endocannabinoids. Eur J Neurosci 39: 467-484.

Hu W, Zhang M, Czeh B, Zhang W, Flugge G (2011). Chronic restraint stress impairs endocannabinoid mediated suppression of GABAergic signaling in the hippocampus of adult male rats. Brain Res Bull 85: 374-379.

Huang YC, Wang SJ, Chiou LC, Gean PW (2003). Mediation of amphetamineinduced long-term depression of synaptic transmission by CB1 cannabinoid receptors in the rat amygdala. J Neurosci 23: 10311-10320.

Hubner C, Bosch D, Gall A, Luthi A, Ehrlich I (2014). Ex vivo dissection of optogenetically activated mPFC and hippocampal inputs to neurons in the basolateral amygdala: implications for fear and emotional memory. Front Behav Neurosci 8: 64

Janak PH, Tye KM (2015). From circuits to behaviour in the amygdala. Nature 517: 284-292.

Jiang W, Zhang Y, Xiao L, Van Cleemput J, Ji SP, Bai G et al (2005). Cannabinoids promote embryonic and adult hippocampus neurogenesis and produce anxiolytic- and antidepressant-like effects. J Clin Invest 115: 3104-3116.

Joels M, Baram TZ (2009). The neuro-symphony of stress. Nat Rev Neurosci 10: 459-466.

Joels M, Fernandez G, Roozendaal B (2011). Stress and emotional memory: a matter of timing. Trends Cogn Sci 15: 280-288.

Johnson LR, Farb C, Morrison JH, McEwen BS, LeDoux JE (2005). Localization of glucocorticoid receptors at postsynaptic membranes in the lateral amygdala. Neuroscience 136: 289-299.

Juhasz G, Chase D, Pegg E, Downey D, Toth ZG, Stones K et al (2009). CNR1 gene is associated with high neuroticism and low agreeableness and interacts with recent negative life events to predict current depressive symptoms. Neuropsychopharmacology 34: 2019-2027.

Kamprath K, Romo-Parra H, Haring M, Gaburro S, Doengi M, Lutz B et al (2011). Short-term adaptation of conditioned fear responses through endocannabinoid signaling in the central amygdala. Neuropsychopharmacology 36: 652-663.

Kano M, Ohno-Shosaku T, Hashimotodani Y, Uchigashima M, Watanabe M (2009). Endocannabinoid-mediated control of synaptic transmission. Physiol Rev 89: 309-380.

Karatsoreos IN, McEwen BS (2011). Psychobiological allostasis: resistance, resilience and vulnerability. Trends Cogn Sci 15: 576-584.
Karst H, Berger S, Erdmann G, Schutz G, Joels M (2010). Metaplasticity of amygdalar responses to the stress hormone corticosterone. Proc Natl Acad Sci USA 107: 14449-14454.

Kathuria S, Gaetani S, Fegley D, Valino F, Duranti A, Tontini A et al (2003). Modulation of anxiety through blockade of anandamide hydrolysis. Nat Med 9: 76-81.

Katona I, Freund TF (2012). Multiple functions of endocannabinoid signaling in the brain. Annu Rev Neurosci 35: 529-558

Kim MJ, Loucks RA, Palmer AL, Brown AC, Solomon KM, Marchante AN et al (2011). The structural and functional connectivity of the amygdala: from normal emotion to pathological anxiety. Behav Brain Res 223: 403-410.

Kim SJ, Park SH, Choi SH, Moon BH, Lee KJ, Kang SW et al (2006). Effects of repeated tianeptine treatment on CRF mRNA expression in non-stressed and chronic mild stress-exposed rats. Neuropharmacology 50: 824-833.

Kinsey SG, O'Neal ST, Long JZ, Cravatt BF, Lichtman AH (2011). Inhibition of endocannabinoid catabolic enzymes elicits anxiolytic-like effects in the marble burying assay. Pharmacol Biochem Behav 98: 21-27.

Kinsey SG, Wise LE, Ramesh D, Abdullah R, Selley DE, Cravatt BF et al (2013). Repeated low-dose administration of the monoacylglycerol lipase inhibitor JZL184 retains cannabinoid receptor type 1-mediated antinociceptive and gastroprotective effects. J Pharmacol Exp Ther 345: 492-501.

Koob GF, Buck CL, Cohen A, Edwards S, Park PE, Schlosburg JE et al (2014). Addiction as a stress surfeit disorder. Neuropharmacology 76(Pt B): 370-382.

Kupferschmidt DA, Klas PG, Erb S (2012). Cannabinoid CB1 receptors mediate the effects of corticotropin-releasing factor on the reinstatement of cocaine seeking and expression of cocaine-induced behavioural sensitization. $\mathrm{Br} J$ Pharmacol 167: 196-206.

Kurrikoff K, Inno J, Matsui T, Vasar E (2008). Stress-induced analgesia in mice: evidence for interaction between endocannabinoids and cholecystokinin. Eur J Neurosci 27: 2147-2155.

Lee TT, Hill MN (2013). Age of stress exposure modulates the immediate and sustained effects of repeated stress on corticolimbic cannabinoid $\mathrm{CB}(1)$ receptor binding in male rats. Neuroscience 249: 106-114.

Lichtman AH, Hawkins EG, Griffin G, Cravatt BF (2002). Pharmacological activity of fatty acid amides is regulated, but not mediated, by fatty acid amide hydrolase in vivo. J Pharmacol Exp Ther 302: 73-79.

Likhtik E, Paz R (2015). Amygdala-prefrontal interactions in (mal)adaptive learning Trends Neurosci 38: 158-166.

Likhtik E, Pelletier JG, Paz R, Pare D (2005). Prefrontal control of the amygdala. J Neurosci 25: 7429-7437.

Liposits Z, Bohn MC (1993). Association of glucocorticoid receptor immunoreactivity with cell membrane and transport vesicles in hippocampal and hypothalamic neurons of the rat. J Neurosci Res 35: 14-19.

Lomazzo E, Bindila L, Remmers F, Lerner R, Schwitter C, Hoheisel U et al (2015). Therapeutic potential of inhibitors of endocannabinoid degradation for the treatment of stress-related hyperalgesia in an animal model of chronic pain. Neuropsychopharmacology 40: 488-501.

Long JZ, Nomura DK, Cravatt BF (2009). Characterization of monoacylglycerol lipase inhibition reveals differences in central and peripheral endocannabinoid metabolism. Chem Biol 16: 744-753.

Mailleux P, Vanderhaeghen JJ (1993). Glucocorticoid regulation of cannabinoid receptor messenger RNA levels in the rat caudate-putamen. An in situ hybridization study. Neurosci Lett 156: 51-53.

Makino S, Gold PW, Schulkin J (1994a). Corticosterone effects on corticotropinreleasing hormone mRNA in the central nucleus of the amygdala and the parvocellular region of the paraventricular nucleus of the hypothalamus. Brain Res 640: 105-112.

Makino S, Gold PW, Schulkin J (1994b). Effects of corticosterone on CRH mRNA and content in the bed nucleus of the stria terminalis; comparison with the effects in the central nucleus of the amygdala and the paraventricular nucleus of the hypothalamus. Brain Res 657: 141-149.

Mangieri RA, Hong Kl, Piomelli D, Sinha R (2009). An endocannabinoid signal associated with desire for alcohol is suppressed in recently abstinent alcoholics. Psychopharmacology (Berl) 205: 63-72.

Manzanares J, Corchero J, Fuentes JA (1999). Opioid and cannabinoid receptormediated regulation of the increase in adrenocorticotropin hormone and corticosterone plasma concentrations induced by central administration of delta (9)-tetrahydrocannabinol in rats. Brain Res 839: 173-179.

Marco EM, Scattoni ML, Rapino C, Ceci C, Chaves N, Macri S et al (2013). Emotional, endocrine and brain anandamide response to social challenge in infant male rats. Psychoneuroendocrinology 38: 2152-2162.

Marco EM, Viveros MP (2009). The critical role of the endocannabinoid system in emotional homeostasis: avoiding excess and deficiencies. Mini Rev Med Chem 9: $1407-1415$. 
Marrs WR, Blankman JL, Horne EA, Thomazeau A, Lin YH, Coy J et al (2010). The serine hydrolase ABHD6 controls the accumulation and efficacy of 2-AG at cannabinoid receptors. Nat Neurosci 13: 951-957.

Marsicano G, Kuner R (2008). Anatomical distribution of receptors, ligands and enzymes in the brain and the spinal cord: circuitries and neurochemistry. In: Kofalvi A (ed). Cannabinoids and the Brain. Springer: New York, USA, pp 161-202.

Marsicano G, Wotjak CT, Azad SC, Bisogno T, Rammes G, Cascio MG et al (2002). The endogenous cannabinoid system controls extinction of aversive memories. Nature 418: 530-534.

Martin M, Ledent C, Parmentier M, Maldonado R, Valverde O (2002). Involvement of CB1 cannabinoid receptors in emotional behaviour. Psychopharmacology (Berl) 159: 379-387.

Matsuda LA, Lolait SJ, Brownstein MJ, Young AC, Bonner TI (1990). Structure of a cannabinoid receptor and functional expression of the cloned cDNA. Nature 346: 561-564.

McEwen BS (2012a). Brain on stress: how the social environment gets under the skin. Proc Natl Acad Sci USA 109(Suppl 2): 17180-17185.

McEwen BS (2012b). The ever-changing brain: cellular and molecular mechanisms for the effects of stressful experiences. Dev Neurobiol 72: 878-890.

McGaugh JL (2015). Consolidating memories. Annu Rev Psychol 66: 1-24.

Mclntyre CK, Hatfield T, McGaugh JL (2002). Amygdala norepinephrine levels after training predict inhibitory avoidance retention performance in rats. Eur $\mathrm{J}$ Neurosci 16: 1223-1226.

McLaughlin RJ, Hill MN, Bambico FR, Stuhr KL, Gobbi G, Hillard CJ et al (2012). Prefrontal cortical anandamide signaling coordinates coping responses to stress through a serotonergic pathway. Eur Neuropsychopharmacol 22: 664-671.

McLaughlin RJ, Hill MN, Dang SS, Wainwright SR, Galea LA, Hillard CJ et al (2013). Upregulation of $\mathrm{CB}(1)$ receptor binding in the ventromedial prefrontal cortex promotes proactive stress-coping strategies following chronic stress exposure. Behav Brain Res 237: 333-337.

McPartland JM, Glass M, Pertwee RG (2007). Meta-analysis of cannabinoid ligand binding affinity and receptor distribution: interspecies differences. $\mathrm{Br} J$ Pharmacol 152: 583-593.

Mechoulam R, Parker LA (2013). The endocannabinoid system and the brain. Annu Rev Psychol 64: 21-47.

Merlo Pich E, Lorang M, Yeganeh M, Rodriguez de Fonseca F, Raber J, Koob GF et al (1995). Increase of extracellular corticotropin-releasing factor-like immunoreactivity levels in the amygdala of awake rats during restraint stress and ethanol withdrawal as measured by microdialysis. J Neurosci 15: 5439-5447.

Mikics E, Vas J, Aliczki M, Halasz J, Haller J (2009). Interactions between the anxiogenic effects of CB1 gene disruption and 5-HT3 neurotransmission. Behav Pharmacol 20: 265-272.

Mitchell PB, Morris MJ (2007). Depression and anxiety with rimonabant. Lancet 370 1671-1672.

Morena M, Campolongo P (2014a). The endocannabinoid system: An emotional buffer in the modulation of memory function. Neurobiol Learn Mem 112C: 30-43.

Morena M, Roozendaal B, Trezza V, Ratano P, Peloso A, Hauer D et al (2014b). Endogenous cannabinoid release within prefrontal-limbic pathways affects memory consolidation of emotional training. Proc Natl Acad Sci USA 111: 18333-18338.

Morozov YM, Torii M, Rakic P (2009). Origin, early commitment, migratory routes, and destination of cannabinoid type 1 receptor-containing interneurons. Cereb Cortex 19(Suppl 1): i78-i89.

Naidu PS, Varvel SA, Ahn K, Cravatt BF, Martin BR, Lichtman AH (2007). Evaluation of fatty acid amide hydrolase inhibition in murine models of emotionality. Psychopharmacology (Berl) 192: 61-70.

Navarria A, Tamburella A, lannotti FA, Micale V, Camillieri G, Gozzo L et al (2014). The dual blocker of FAAH/TRPV1 $\mathrm{N}$-arachidonoylserotonin reverses the behavioral despair induced by stress in rats and modulates the HPA-axis. Pharmacol Res 87: 151-159.

Neumeister A, Normandin MD, Pietrzak RH, Piomelli D, Zheng MQ, Gujarro-Anton A et al (2013). Elevated brain cannabinoid CB receptor availability in post-traumatic stress disorder: a positron emission tomography study. Mol Psychiatry 18: 1034-1040.

Neumeister A, Seidel J, Ragen BJ, Pietrzak RH (2015). Translational evidence for a role of endocannabinoids in the etiology and treatment of posttraumatic stress disorder. Psychoneuroendocrinology 51: 577-584.

Newsom RJ, Osterlund C, Masini CV, Day HE, Spencer RL, Campeau S (2012). Cannabinoid receptor type 1 antagonism significantly modulates basal and loud noise induced neural and hypothalamic-pituitary-adrenal axis responses in male Sprague-Dawley rats. Neuroscience 204: 64-73.

Ohno-Shosaku T, Kano M (2014). Endocannabinoid-mediated retrograde modulation of synaptic transmission. Curr Opin Neurobiol 29: 1-8.

Oitzl MS, de Kloet ER (1992). Selective corticosteroid antagonists modulate specific aspects of spatial orientation learning. Behav Neurosci 106: 62-71.
Olango WM, Roche M, Ford GK, Harhen B, Finn DP (2012). The endocannabinoid system in the rat dorsolateral periaqueductal grey mediates fear-conditioned analgesia and controls fear expression in the presence of nociceptive tone. $\mathrm{Br} \mathrm{J}$ Pharmacol 165: 2549-2560.

Oropeza VC, Mackie K, Van Bockstaele EJ (2007). Cannabinoid receptors are localized to noradrenergic axon terminals in the rat frontal cortex. Brain Res 1127: 36-44.

Pamplona FA, Bitencourt RM, Takahashi RN (2008). Short- and long-term effects of cannabinoids on the extinction of contextual fear memory in rats. Neurobiol Learn Mem 90: 290-293

Patel S, Cravatt BF, Hillard CJ (2005a). Synergistic interactions between cannabinoids and environmental stress in the activation of the central amygdala. Neuropsychopharmacology 30: 497-507.

Patel S, Hillard CJ (2008). Adaptations in endocannabinoid signaling in response to repeated homotypic stress: a novel mechanism for stress habituation. Eur J Neurosci 27: 2821-2829.

Patel S, Kingsley PJ, Mackie K, Marnett LJ, Winder DG (2009). Repeated homotypic stress elevates 2-arachidonoylglycerol levels and enhances short-term endocannabinoid signaling at inhibitory synapses in basolateral amygdala. Neuropsychopharmacology 34: 2699-2709.

Patel S, Roelke CT, Rademacher DJ, Cullinan WE, Hillard CJ (2004). Endocannabinoid signaling negatively modulates stress-induced activation of the hypothalamic-pituitary-adrenal axis. Endocrinology 145: 5431-5438.

Patel S, Roelke CT, Rademacher DJ, Hillard CJ (2005b). Inhibition of restraint stressinduced neural and behavioural activation by endogenous cannabinoid signalling. Eur J Neurosci 21: 1057-1069.

Pecoraro N, Dallman MF, Warne JP, Ginsberg AB, Laugero KD, la Fleur SE et al (2006). From Malthus to motive: how the HPA axis engineers the phenotype, yoking needs to wants. Prog Neurobiol 79: 247-340.

Pertwee RG (2005). Pharmacological actions of cannabinoids. Handb Exp Pharmacol 168: 1-51.

Pittenger C, Duman RS (2008). Stress, depression, and neuroplasticity: a convergence of mechanisms. Neuropsychopharmacology 33: 88-109.

Popoli M, Yan Z, McEwen BS, Sanacora G (2011). The stressed synapse: the impact of stress and glucocorticoids on glutamate transmission. Nat Rev Neurosci 13: 22-37.

Pruessner JC, Dedovic K, Pruessner M, Lord C, Buss C, Collins L et al (2010). Stress regulation in the central nervous system: evidence from structural and functional neuroimaging studies in human populations-2008 Curt Richter Award Winner. Psychoneuroendocrinology 35: 179-191.

Qin Z, Zhou X, Pandey NR, Vecchiarelli HA, Stewart CA, Zhang X et al (2015). Chronic stress induces anxiety via an amygdalar intracellular cascade that impairs endocannabinoid signaling. Neuron 85: 1319-1331.

Quirarte GL, Roozendaal B, McGaugh JL (1997). Glucocorticoid enhancement of memory storage involves noradrenergic activation in the basolateral amygdala. Proc Natl Acad Sci USA 94: 14048-14053.

Racz I, Bilkei-Gorzo A, Toth ZE, Michel K, Palkovits M, Zimmer A (2003). A critical role for the cannabinoid $\mathrm{CB} 1$ receptors in alcohol dependence and stressstimulated ethanol drinking. J Neurosci 23: 2453-2458.

Rademacher DJ, Hillard CJ (2007). Interactions between endocannabinoids and stress-induced decreased sensitivity to natural reward. Prog Neuropsychopharmacol Biol Psychiatry 31: 633-641.

Rademacher DJ, Meier SE, Shi L, Ho WS, Jarrahian A, Hillard CJ (2008). Effects of acute and repeated restraint stress on endocannabinoid content in the amygdala, ventral striatum, and medial prefrontal cortex in mice. Neuropharmacology 54: 108-116.

Radley JJ (2012). Toward a limbic cortical inhibitory network: implications for hypothalamic-pituitary-adrenal responses following chronic stress. Front Behav Neurosci 6: 7 .

Ramikie TS, Nyilas R, Bluett RJ, Gamble-George JC, Hartley ND, Mackie K et al (2014). Multiple mechanistically distinct modes of endocannabinoid mobilization at central amygdala glutamatergic synapses. Neuron 81: 1111-1125.

Ramikie TS, Patel S (2012). Endocannabinoid signaling in the amygdala: anatomy, synaptic signaling, behavior, and adaptations to stress. Neuroscience 204: 38-52.

Refojo D, Echenique C, Muller MB, Reul JM, Deussing JM, Wurst W et al (2005). Corticotropin-releasing hormone activates ERK1/2 MAPK in specific brain areas. Proc Natl Acad Sci USA 102: 6183-6188.

Reich CG, Mihalik GR, Iskander AN, Seckler JC, Weiss MS (2013). Adolescent chronic mild stress alters hippocampal CB1 receptor-mediated excitatory neurotransmission and plasticity. Neuroscience 253: 444-454.

Reich CG, Taylor ME, McCarthy MM (2009). Differential effects of chronic unpredictable stress on hippocampal CB1 receptors in male and female rats. Behav Brain Res 203: 264-269. 
Rey AA, Purrio M, Viveros MP, Lutz B (2012). Biphasic effects of cannabinoids in anxiety responses: $\mathrm{CB} 1$ and $\mathrm{GABA}(\mathrm{B})$ receptors in the balance of GABAergic and glutamatergic neurotransmission. Neuropsychopharmacology 37: 2624-2634.

Roberto M, Cruz M, Bajo M, Siggins GR, Parsons LH, Schweitzer P (2010). The endocannabinoid system tonically regulates inhibitory transmission and depresses the effect of ethanol in central amygdala. Neuropsychopharmacology 35: 1962-1972.

Roberts CJ, Stuhr KL, Hillard CJ (2012). Swim stress differentially affects limbic contents of 2-arachidonoylglycerol and 2-oleoylglycerol. Neuroscience 204: 74-82.

Roberts CJ, Stuhr KL, Hutz MJ, Raff H, Hillard CJ (2014). Endocannabinoid signaling in hypothalamic-pituitary-adrenocortical axis recovery following stress: effects of indirect agonists and comparison of male and female mice. Pharmacol Biochem Behav 117: 17-24.

Rodrigues SM, LeDoux JE, Sapolsky RM (2009). The influence of stress hormones on fear circuitry. Annu Rev Neurosci 32: 289-313.

Roozendaal B (2000). 1999 Curt P. Richter award. Glucocorticoids and the regulation of memory consolidation. Psychoneuroendocrinology 25: 213-238.

Roozendaal B, Brunson KL, Holloway BL, McGaugh JL, Baram TZ (2002). Involvement of stress-released corticotropin-releasing hormone in the basolateral amygdala in regulating memory consolidation. Proc Natl Acad Sci USA 99: 13908-13913.

Roozendaal B, McEwen BS, Chattarji S (2009). Stress, memory and the amygdala. Nat Rev Neurosci 10: 423-433.

Roozendaal B, McGaugh JL (1996). Amygdaloid nuclei lesions differentially affect glucocorticoid-induced memory enhancement in an inhibitory avoidance task. Neurobiol Learn Mem 65: 1-8.

Roozendaal B, McGaugh JL (1997). Glucocorticoid receptor agonist and antagonist administration into the basolateral but not central amygdala modulates memory storage. Neurobiol Learn Mem 67: 176-179.

Rossi S, De Chiara V, Musella A, Kusayanagi H, Mataluni G, Bernardi G et al (2008). Chronic psychoemotional stress impairs cannabinoid-receptor-mediated control of GABA transmission in the striatum. J Neurosci 28: 7284-7292.

Rossi S, De Chiara V, Musella A, Sacchetti L, Cantarella C, Castelli M et al (2010). Preservation of striatal cannabinoid $\mathrm{CB} 1$ receptor function correlates with the antianxiety effects of fatty acid amide hydrolase inhibition. Mol Pharmacol 78: 260-268.

Rubino T, Realini N, Castiglioni C, Guidali C, Vigano D, Marras E et al (2008). Role in anxiety behavior of the endocannabinoid system in the prefrontal cortex. Cereb Cortex 18: 1292-1301.

Ruehle S, Remmers F, Romo-Parra H, Massa F, Wickert M, Wortge S et al (2013). Cannabinoid CB1 receptor in dorsal telencephalic glutamatergic neurons: distinctive sufficiency for hippocampus-dependent and amygdala-dependent synaptic and behavioral functions. J Neurosci 33: 10264-10277.

Salehi B, Cordero MI, Sandi C (2010). Learning under stress: the inverted-U-shape function revisited. Learn Mem 17: 522-530.

Sanchis-Segura C, Cline BH, Marsicano G, Lutz B, Spanagel R (2004). Reduced sensitivity to reward in CB1 knockout mice. Psychopharmacology (Berl) 176: 223-232.

Sandi C, Cordero MI, Ugolini A, Varea E, Caberlotto L, Large CH (2008). Chronic stress-induced alterations in amygdala responsiveness and behavior-modulation by trait anxiety and corticotropin-releasing factor systems. Eur J Neurosci 28: 1836-1848.

Sandi C, Rose SP (1994). Corticosterone enhances long-term retention in one-dayold chicks trained in a weak passive avoidance learning paradigm. Brain Res 647 : 106-112.

Santucci V, Storme JJ, Soubrie P, Le Fur G (1996). Arousal-enhancing properties of the CB1 cannabinoid receptor antagonist SR 141716A in rats as assessed by electroencephalographic spectral and sleep-waking cycle analysis. Life Sci 58: PL103-PL110.

Schlosburg JE, Blankman JL, Long JZ, Nomura DK, Pan B, Kinsey SG et al (2010). Chronic monoacylglycerol lipase blockade causes functional antagonism of the endocannabinoid system. Nat Neurosci 13: 1113-1119.

Sciolino NR, Zhou W, Hohmann AG (2011). Enhancement of endocannabinoid signaling with JZL184, an inhibitor of the 2-arachidonoylglycerol hydrolyzing enzyme monoacylglycerol lipase, produces anxiolytic effects under conditions of high environmental aversiveness in rats. Pharmacol Res 64: 226-234.

Senst L, Bains J (2014). Neuromodulators, stress and plasticity: a role for endocannabinoid signalling. J Exp Biol 217: 102-108.

Shonesy BC, Bluett RJ, Ramikie TS, Baldi R, Hermanson DJ, Kingsley PJ et al (2014). Genetic disruption of 2-arachidonoylglycerol synthesis reveals a key role for endocannabinoid signaling in anxiety modulation. Cell Rep 9: 1644-1653.

Singh ME, Verty AN, Price I, McGregor IS, Mallet PE (2004). Modulation of morphineinduced Fos-immunoreactivity by the cannabinoid receptor antagonist SR 141716. Neuropharmacology 47: 1157-1169.
Sipe JC, Chiang K, Gerber AL, Beutler E, Cravatt BF (2002). A missense mutation in human fatty acid amide hydrolase associated with problem drug use. Proc Natl Acad Sci USA 99: 8394-8399.

Sipe JC, Scott TM, Murray S, Harismendy O, Simon GM, Cravatt BF et al (2010). Biomarkers of endocannabinoid system activation in severe obesity. PLoS One 5: e8792.

Sparta DR, Jennings JH, Ung RL, Stuber GD (2013). Optogenetic strategies to investigate neural circuitry engaged by stress. Behav Brain Res 255: 19-25.

Steiner MA, Marsicano G, Nestler EJ, Holsboer F, Lutz B, Wotjak CT (2008). Antidepressant-like behavioral effects of impaired cannabinoid receptor type 1 signaling coincide with exaggerated corticosterone secretion in mice. Psychoneuroendocrinology 33: 54-67.

Steiner MA, Wotjak CT (2008). Role of the endocannabinoid system in regulation of the hypothalamic-pituitary-adrenocortical axis. Prog Brain Res 170: 397-432.

Sterrenburg L, Gaszner B, Boerrigter J, Santbergen L, Bramini M, Elliott E et al (2011). Chronic stress induces sex-specific alterations in methylation and expression of corticotropin-releasing factor gene in the rat. PLoS One 6: e28128.

Sugiura T, Kondo S, Sukagawa A, Nakane S, Shinoda A, Itoh K et al (1995). 2Arachidonoylglycerol: a possible endogenous cannabinoid receptor ligand in brain. Biochem Biophys Res Commun 215: 89-97.

Sumislawski JJ, Ramikie TS, Patel S (2011). Reversible gating of endocannabinoid plasticity in the amygdala by chronic stress: a potential role for monoacylglycerol lipase inhibition in the prevention of stress-induced behavioral adaptation. Neuropsychopharmacology 36: 2750-2761.

Suzuki A, Josselyn SA, Frankland PW, Masushige S, Silva AJ, Kida S (2004). Memory reconsolidation and extinction have distinct temporal and biochemical signatures. J Neurosci 24: 4787-4795.

Swanson LW, Simmons DM (1989). Differential steroid hormone and neural influences on peptide mRNA levels in $\mathrm{CRH}$ cells of the paraventricular nucleus: a hybridization histochemical study in the rat. J Comp Neurol 285: 413-435.

Swartz JR, Knodt AR, Radtke SR, Hariri AR (2015). A neural biomarker of psychological vulnerability to future life stress. Neuron 85: 505-511.

Tallett AJ, Blundell JE, Rodgers RJ (2007). Grooming, scratching and feeding: role of response competition in acute anorectic response to rimonabant in male rats. Psychopharmacology (Berl) 195: 27-39.

Tan H, Lauzon NM, Bishop SF, Chi N, Bechard M, Laviolette SR (2011). Cannabinoid transmission in the basolateral amygdala modulates fear memory formation via functional inputs to the prelimbic cortex. J Neurosci 31: 5300-5312.

Topol EJ, Bousser MG, Fox KA, Creager MA, Despres JP, Easton JD et al (2010). Rimonabant for prevention of cardiovascular events (CRESCENDO): a randomised, multicentre, placebo-controlled trial. Lancet 376: 517-523.

Ulrich-Lai YM, Herman JP (2009). Neural regulation of endocrine and autonomic stress responses. Nat Rev Neurosci 10: 397-409.

Uriguen L, Perez-Rial S, Ledent C, Palomo T, Manzanares J (2004). Impaired action of anxiolytic drugs in mice deficient in cannabinoid CB1 receptors. Neuropharmacology 46: 966-973.

Valverde O, Ledent C, Beslot F, Parmentier M, Roques BP (2000). Reduction of stress-induced analgesia but not of exogenous opioid effects in mice lacking CB1 receptors. Eur J Neurosci 12: 533-539.

Van Sickle MD, Duncan M, Kingsley PJ, Mouihate A, Urbani P, Mackie Ket al (2005). Identification and functional characterization of brainstem cannabinoid CB2 receptors. Science 310: 329-332.

Varvel SA, Lichtman AH (2002). Evaluation of CB1 receptor knockout mice in the Morris water maze. J Pharmacol Exp Ther 301: 915-924.

Vaughn LK, Mantsch JR, Vranjkovic O, Stroh G, Lacourt M, Kreutter M et al (2012). Cannabinoid receptor involvement in stress-induced cocaine reinstatement: potential interaction with noradrenergic pathways. Neuroscience 204: 117-124.

Veinante P, Yalcin I, Barrot M (2013). The amygdala between sensation and affect: a role in pain. $J \mathrm{Mol}$ Psychiatry 1: 9.

Wade MR, Degroot A, Nomikos GG (2006). Cannabinoid CB1 receptor antagonism modulates plasma corticosterone in rodents. Eur J Pharmacol 551: 162-167.

Wamsteeker Cusulin JI, Senst L, Teskey GC, Bains JS (2014). Experience salience gates endocannabinoid signaling at hypothalamic synapses. J Neurosci 34: 6177-6181.

Wamsteeker JI, Kuzmiski JB, Bains JS (2010). Repeated stress impairs endocannabinoid signaling in the paraventricular nucleus of the hypothalamus. J Neurosci 30: 11188-11196.

Wang J, Shen RY, Haj-Dahmane S (2012a). Endocannabinoids mediate the glucocorticoid-induced inhibition of excitatory synaptic transmission to dorsal raphe serotonin neurons. J Physiol 590: 5795-5808.

Wang M, Hill MN, Zhang L, Gorzalka BB, Hillard CJ, Alger BE (2012b). Acute restraint stress enhances hippocampal endocannabinoid function via glucocorticoid receptor activation. J Psychopharmacol 26: 56-70. 
Wang W, Sun D, Pan B, Roberts CJ, Sun X, Hillard CJ et al (2010). Deficiency in endocannabinoid signaling in the nucleus accumbens induced by chronic unpredictable stress. Neuropsychopharmacology 35: 2249-2261.

Wittmann G, Deli L, Kallo I, Hrabovszky E, Watanabe M, Liposits Z et al (2007). Distribution of type 1 cannabinoid receptor (CB1)-immunoreactive axons in the mouse hypothalamus. J Comp Neurol 503: 270-279.

Wolkers CP, Barbosa Junior A, Menescal-de-Oliveira L, Hoffmann A (2015). Acute administration of a cannabinoid CB1 receptor antagonist impairs stress-induced antinociception in fish. Physiol Behav 142: 37-41.

Yoshida T, Uchigashima M, Yamasaki M, Katona I, Yamazaki M, Sakimura K et al (2011). Unique inhibitory synapse with particularly rich endocannabinoid signaling machinery on pyramidal neurons in basal amygdaloid nucleus. Proc Natl Acad Sci USA 108: 3059-3064.

Zhang Z, Wang W, Zhong P, Liu SJ, Long JZ, Zhao L et al (2015). Blockade of 2 arachidonoylglycerol hydrolysis produces antidepressant-like effects and enhances adult hippocampal neurogenesis and synaptic plasticity. Hippocampus 25: 16-26.

Zhong P, Wang W, Pan B, Liu X, Zhang Z, Long JZ et al (2014). Monoacylglycerol lipase inhibition blocks chronic stress-induced depressive-like behaviors via activation of mTOR signaling. Neuropsychopharmacology 39: 1763-1776.

Zoppi S, Perez Nievas BG, Madrigal JL, Manzanares J, Leza JC, Garcia-Bueno B (2011). Regulatory role of cannabinoid receptor 1 in stress-induced excitotoxicity and neuroinflammation. Neuropsychopharmacology 36: 805-818. 